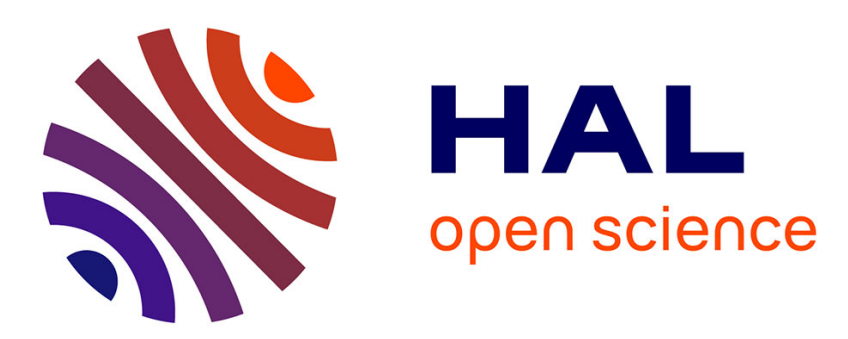

\title{
TMP-cadmiate: A base for Efficient and Chemoselective Deprotonative Metallation Reactions of Aromatic Compounds
}

Florence Mongin, Masanobu Uchiyama

\section{- To cite this version:}

Florence Mongin, Masanobu Uchiyama. TMP-cadmiate: A base for Efficient and Chemoselective Deprotonative Metallation Reactions of Aromatic Compounds. Current Organic Chemistry, 2011, 15, pp.2340-2361. 10.2174/138527211796150651 . hal-01053743

HAL Id: hal-01053743

https://hal-univ-rennes1.archives-ouvertes.fr/hal-01053743

Submitted on 1 Aug 2014

HAL is a multi-disciplinary open access archive for the deposit and dissemination of scientific research documents, whether they are published or not. The documents may come from teaching and research institutions in France or abroad, or from public or private research centers.
L'archive ouverte pluridisciplinaire HAL, est destinée au dépôt et à la diffusion de documents scientifiques de niveau recherche, publiés ou non, émanant des établissements d'enseignement et de recherche français ou étrangers, des laboratoires publics ou privés. 


\title{
TMP-cadmiate: A base for Efficient and Chemoselective Deprotonative Metallation
}

\section{Reactions of Aromatic Compounds}

Florence Mongin* and Masanobu Uchiyama*

Chimie et Photonique Moléculaires, UMR 6510 CNRS, Université de Rennes 1, Bâtiment 10A, Case 1003, Campus Scientifique de Beaulieu, 35042 Rennes, France. E-mail: florence.mongin@univ-rennes1.fr

The Institute of Physical and Chemical Research, RIKEN

2-1 Hirosawa, Wako-shi, Saitama 351-0198, Japan. E-mail: uchi_yama@riken.jp

\begin{abstract}
Efficient deprotonative cadmiation reactions of functionalized aromatics including heterocycles have been realized using TMP-cadmiate, $(\mathrm{TMP})_{3} \mathrm{CdLi}(\mathrm{TMP}=2,2,6,6$ tetramethylpiperidino). The reagent is compatible with reactive functional groups (amide, ester, nitrile and even ketone functions), heavy halogens ( $\mathrm{Br}$, I), five-membered aromatic heterocycles (furan, thiophene, oxazole, thiazole, and pyrrole derivatives) and even aromatic aza-heterocycles (pyridine, diazine compounds). Some heterocycles benefiting from doubly activated positions can be dimetallated at room temperature. The deprotonative cadmiation pathways/mechanisms have been studied using computational/theoretical techniques. The lithium arylcadmiates such generated have been evidenced using iodine. Alternative trappings of the species are palladium-catalyzed cross-coupling reactions or simple quench with acid chlorides.
\end{abstract}

Keywords: cadmium, lithium, deprotonative metallation, DFT calculations, aromatic, heterocycle, cross-coupling, electrophile 


\section{INTRODUCTION}

The deprotonative metallation has been widely used as a powerful method for the regioselective functionalization of aromatic compounds [1]. Various strong bases such as alkyllithiums (butyllithium, sec-butyllithium, tert-butyllithium, and methyllithium...), phenyllithiums (phenyllithium itself and mesityllithium) and lithium dialkylamides (notably lithium 2,2,6,6-tetramethylpiperidide (LiTMP) and lithium diisopropylamide (LiDA)) have been largely employed for this purpose. They are either commercially available or can be readily prepared in solvents such as ethers and alkanes in which they are soluble. However, because of their highly polar nature, their use for the functionalization of sensitive aromatic substrates, such as those bearing functions or being prone to nucleophilic attacks, requires strictly controlled conditions. This is also true for hindered lithium dialkylamides due to the formation of aryllithiums of high reactivity through deprotonation. Thus, when possible, such conversions for example require in situ trapping or extremely low reaction temperatures. Recourse to softer magnesium diamides can improve the chemoselectivity of deprotonation reactions, but to the detriment of their efficiency [2].

In the absence of polar solvents, activating agents or directing groups, the use of lithium compounds on their own as bases is limited. It is known from decades that tetrahydrofuran (THF) is the solvent of choice to perform most of the deproto-metallation reactions. Another representative activation way is the formation of chelates between alkyllithiums and $N, N, N^{\prime}, N^{\prime}$-tetramethylethylenediamine (TMEDA) with disaggregation of the base [1].

The use of metal additives in order to get more efficient or more chemoselective bases is a challenging field. Various $(R)_{n}\left(R^{\prime}\right)_{n^{\prime}} M L i\left(M=\right.$ metal, $R, R^{\prime}=$ alkyl, amino, chloro... $)$ type compounds already prepared behave as superbases since such species exhibit behaviours that cannot be reproduced by the monometallic compounds on their own. Among them, LIC-KOR 
$(\mathrm{LIC}=($ common $)$ butyllithium, KOR $=$ potassium tert-butoxide $)$ first described by Schlosser [3] and Lochmann [4], and BuLi-LiDMAE (DMAE = 2-dimethylaminoethoxide) introduced by Caubère [5] and developed further by Gros and Fort in the pyridine series [6] are wellknown examples of powerful RR'MLi mixtures of organolithiums and $\mathrm{M}$ alkali metal alkoxides.

More recently, $(\mathrm{R})_{\mathrm{n}}\left(\mathrm{R}^{\prime}\right)_{\mathrm{n}}$ 'MLi type compounds with $\mathrm{M}$ different from an alkali metal have also been described for their metallation ability by different groups [7]. These species display a large panel of reactivities, depending on both the metal $\mathrm{M}$ and the groups connected to it.

By combining soft organometallic compounds with alkali (or alkali earth metal) additives (e.g. LiTMP or $\mathrm{LiCl}$ ), bases have been prepared and used to generate functionalized aromatic compounds. Examples are $\mathrm{R}_{2} \mathrm{Zn}(\mathrm{TMP}) \mathrm{Li}(\cdot \mathrm{TMEDA})\left(\mathrm{R}={ }^{t} \mathrm{Bu}, \mathrm{Bu}\right.$, or $\mathrm{Me}$; $\mathrm{TMP}=$ 2,2,6,6-tetramethylpiperidino) (described by the groups of Kondo, Uchiyama, Mulvey and Hevia) [8], (TMP) ${ }_{2} \mathrm{Zn} \cdot 2 \mathrm{MgCl}_{2} \cdot 2 \mathrm{LiCl}[9]$ and TMPZnCl$\cdot \mathrm{LiCl}[10]$ (Knochel), ${ }^{i} \mathrm{Bu}_{3} \mathrm{Al}(\mathrm{TMP}) \mathrm{Li}$ (Uchiyama and Mulvey) [11], $\quad \mathrm{Al}(\mathrm{TMP})_{3} \cdot 3 \mathrm{LiCl} \quad($ Knochel) [12], $\left(\mathrm{Me}_{3} \mathrm{SiCH}_{2}\right)_{2} \mathrm{Mn}$ (TMP)Li-TMEDA (Mulvey) [13], and $\mathrm{MeCu}(\mathrm{TMP})(\mathrm{CN}) \mathrm{Li}_{2}$ (Uchiyama and Wheatley) [14].

We recently prepared different mixed bases from TMEDA chelates of metal salts, $\mathrm{CuCl}_{2}$. TMEDA [15], $\mathrm{ZnCl}_{2} \cdot$ TMEDA [16] or $\mathrm{CdCl}_{2} \cdot$ TMEDA [17], and LiTMP (Scheme 1). From $\mathrm{CuCl}_{2}$.TMEDA, after addition of 1 equivalent of butyllithium to allow the reduction to copper(I), it is possible to prepare a base, assumed to be (TMP) ${ }_{2} \mathrm{CuLi}$, by using 2 equivalents of LiTMP [18]. By reacting $\mathrm{ZnCl}_{2}$. TMEDA with 3 equivalents of LiTMP, a 1:1 mixture of LiTMP and (TMP) $)_{2} \mathrm{Zn}$ is obtained, as shown on the basis of NMR spectroscopy and DFT studies [19]. In contrast, from $\mathrm{CdCl}_{2}$. TMEDA, putative (TMP) $)_{3} \mathrm{CdLi}$ is formed under the same reaction conditions [20] (Scheme 2). 


$$
\begin{aligned}
& \text { BuLi } \\
& \text { (1 equiv) LiTMP } \\
& \mathrm{CuCl}_{2} \text {. TMEDA } \underset{0^{\circ} \mathrm{C}}{\stackrel{\text { THF }}{\longrightarrow}}[\mathrm{CuCl}] \stackrel{(2 \text { equiv })}{\underset{0^{\circ} \mathrm{C}}{\longrightarrow}} \quad(\mathrm{TMP})_{2} \mathrm{CuLi} \\
& \mathrm{ZnCl}_{2} \cdot \mathrm{TMEDA}+\mathrm{LiTMP}(3 \text { equiv }) \quad \stackrel{\mathrm{THF}}{\underset{0^{\circ} \mathrm{C}}{\longrightarrow}} \quad(\mathrm{TMP})_{2} \mathrm{Zn}+\mathrm{LiTMP} \\
& \mathrm{CdCl}_{2} \cdot \mathrm{TMEDA}+\mathrm{LiTMP}\left(3 \text { equiv) } \quad \underset{0^{\circ} \mathrm{C}}{\stackrel{\mathrm{THF}}{\longrightarrow}}(\mathrm{TMP})_{3} \mathrm{CdLi}\right.
\end{aligned}
$$

Scheme 1. Preparation of different lithium-metal combinations
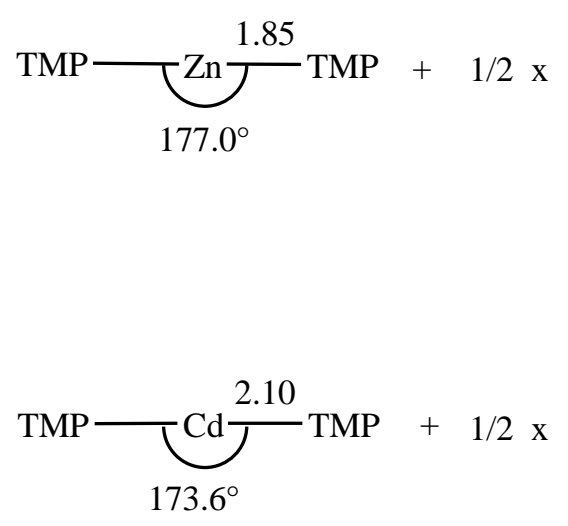
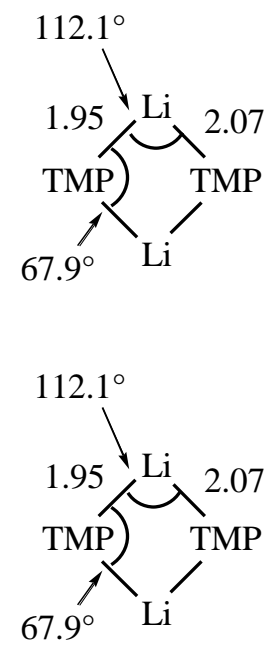
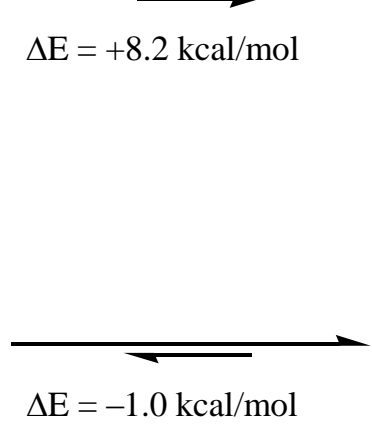
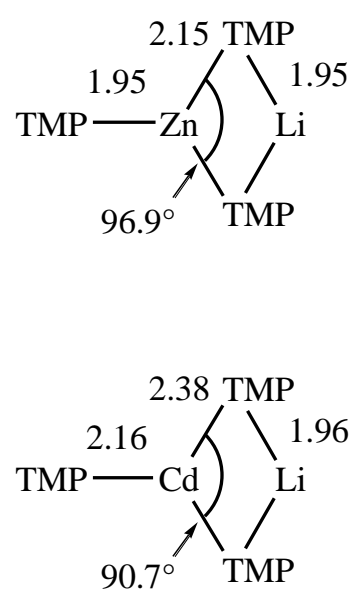

Scheme 2. Bond lengths (in $\AA$ ) at B3LYP/6-31G* (SVP basis set for Zn, Cd, or In)

Wittig and co-workers reported the synthesis of $\mathrm{Ph}_{3} \mathrm{BeLi}, \mathrm{Ph}_{3} \mathrm{MgLi}, \mathrm{Ph}_{3} \mathrm{ZnLi}$, $\mathrm{Ph}_{7} \mathrm{Zn}_{2} \mathrm{Li}_{3}, \mathrm{Ph}_{3} \mathrm{CdLi}$ and $\mathrm{Ph}_{3} \mathrm{HgLi}$, and their ability to deprotonate fluorene in diethyl ether [21]. Quenching with $\mathrm{CO}_{2}$ and subsequent acidic work-up afforded diphenyleneacetic acid in yields of $0 \%$ (after 2 weeks reaction time), 47\% (after 3 days), 16\% (after 10 days), 44\% (after 10 days), 64\% (after 3 days) and 84\% (after 3 days), respectively. In 1951 these results were analyzed as a measure of the dissociation of such complexes into the original diphenylmetal and phenyllithium. The more recent discovery of the basic properties of lithium 
ate compounds such as magnesiates [7] and zincates [7,8] led chemists to consider these results from another angle, and prompted us to study the deproto-metallation of aromatic rings using lithium-metal ate bases with bigger central metals.

\section{SYNERGY OF THE DEPROTONATIVE METALLATION REACTIONS USING} TMP-CADMIATE (Table 1) [20,22]

Using anisole (1a) as substrate, the metallation reactions performed in THF at room temperature by combining 0.50 equivalent of $\mathrm{CdCl}_{2}$. TMEDA and 1.5 equivalents of LiTMP, followed by subsequent trapping with elemental iodine after $2 \mathrm{~h}$, proceeded in $75 \%$ yield (entry 1). The synergy of the reaction was demonstrated using either LiTMP (1 equivalent) or $(\mathrm{TMP})_{2} \mathrm{Cd}$ (1 equivalent). Under the same reaction conditions, the iodide $\mathbf{1 b}$ was isolated in $9 \%$ yield using the former, and did not form using the latter (entries 2 and 3). A possible effect of lithium chloride [23] or TMEDA [24] on the course of the reaction was discarded. Indeed, using LiTMP (1 equiv) with either $\mathrm{LiCl}$ ( 2 equiv) or TMEDA (1 equiv) or both did not result in significant changes (14\% yield in the presence of TMEDA alone, but only traces of $\mathbf{1 b}$ identified in the presence of $\mathrm{LiCl}$ ) (entries 4 and 5).

Since lithium zincates bearing alkyl and amino groups are efficient bases, $(\mathrm{TMP})_{3} \mathrm{CdLi}$ was compared with $\mathrm{BuCd}(\mathrm{TMP})_{2} \mathrm{Li}, \mathrm{Bu}_{2} \mathrm{Cd}(\mathrm{TMP}) \mathrm{Li}$, and $\mathrm{Bu}_{3} \mathrm{CdLi}$ (as well as with the corresponding zinc-lithium mixtures). Using anisole (1a) as substrate, metallation took place but in decidedly lower yields, decreasing with the number of TMP groups (entries 6-8). Replacing the butyl group(s) with sec-butyl, tert-butyl and trimethylsilylmethyl group(s) showed that it was possible to replace one of the TMP groups with a sec-butyl group (entries 9-15). It proved similarly possible to replace one of the TMP groups with a piperidino (Pip) or a diisopropylamino (DA) group (entries 16-20). 
Table 1. Metallation of anisole (1a) using different bases followed by trapping with $\mathrm{I}_{2}$.<smiles>COc1ccccc1</smiles>

1a
1) Base (n equiv)

THF, rt, $2 \mathrm{~h}$

2) $I_{2}$<smiles>COc1ccccc1I</smiles>

$1 \mathrm{~b}$

\begin{tabular}{|c|c|c|}
\hline Entry & Base (n equiv) & Yield (\%) \\
\hline 1 & $(\mathrm{TMP})_{3} \mathrm{CdLi}(0.5$ equiv $)$ & $75(84)^{a}$ \\
\hline 2 & LiTMP (1 equiv) & 9 \\
\hline 3 & $(\mathrm{TMP})_{2} \mathrm{Cd}(1$ equiv $)$ & 0 \\
\hline 4 & $\operatorname{LiTMP}(1$ equiv) $+\mathrm{LiCl}$ (2 equiv) & traces \\
\hline 5 & LiTMP (1 equiv) + TMEDA (1 equiv) & 14 \\
\hline 6 & $\operatorname{BuCd}(\mathrm{TMP})_{2} \mathrm{Li}$ ( 0.5 equiv) & $34(78)^{b}(79)^{a, b}$ \\
\hline 7 & $\mathrm{Bu}_{2} \mathrm{Cd}(\mathrm{TMP}) \mathrm{Li}$ ( 0.5 equiv) & $7(28)^{b}(20)^{a, b}$ \\
\hline 8 & $\mathrm{Bu}_{3} \mathrm{CdLi}$ ( 0.5 equiv) & $9(28)^{a, b}$ \\
\hline 9 & ${ }^{s} \mathrm{Bu}_{2} \mathrm{Cd}(\mathrm{TMP}) \mathrm{Li}$ (1 equiv) & $8(5)^{a}$ \\
\hline 10 & ${ }^{s} \mathrm{BuCd}(\mathrm{TMP})_{2} \mathrm{Li}$ (1 equiv) & $75(73)^{a}$ \\
\hline 11 & ${ }^{t} \mathrm{Bu}_{2} \mathrm{Cd}(\mathrm{TMP}) \mathrm{Li}$ (1 equiv) & $3(44)^{a}$ \\
\hline 12 & ${ }^{t} \mathrm{BuCd}(\mathrm{TMP})_{2} \mathrm{Li}$ (1 equiv) & $39(65)^{a}$ \\
\hline 13 & $\left(\mathrm{TMSCH}_{2}\right)_{3} \mathrm{CdLi}$ (1 equiv) & $0(0)^{a}$ \\
\hline
\end{tabular}




\begin{tabular}{|l|l|l|}
\hline 14 & $\left(\mathrm{TMSCH}_{2}\right)_{2} \mathrm{Cd}(\mathrm{TMP}) \mathrm{Li}^{c}(1$ equiv $)$ & $13(0)^{a}$ \\
\hline 15 & $\left(\mathrm{TMSCH}_{2}\right) \mathrm{Cd}(\mathrm{TMP})_{2} \mathrm{Li}^{c}(1$ equiv $)$ & $51(74)^{a}$ \\
\hline 16 & $(\mathrm{Pip})_{3} \mathrm{CdLi}^{c}(1$ equiv $)$ & $0(0)^{a}$ \\
\hline 17 & $(\mathrm{Pip}) \mathrm{Cd}(\mathrm{TMP})_{2} \mathrm{Li}^{c}(1$ equiv $)$ & $75(48)^{a}$ \\
\hline 18 & $(\mathrm{DA})_{3} \mathrm{CdLi}{ }^{c}\left(1 \mathrm{equiv}^{a}\right.$ & $42(16)^{a}$ \\
\hline 19 & $(\mathrm{TMP}) \mathrm{Cd}(\mathrm{DA})_{2} \mathrm{Li}^{c}(1$ equiv $)$ & $39(38)^{a}$ \\
\hline 20 & $(\mathrm{DA}) \mathrm{Cd}(\mathrm{TMP})_{2} \mathrm{Li}^{c}(1$ equiv $)$ & $84(73)^{a}$ \\
\hline
\end{tabular}

${ }^{a}$ Using the corresponding Li-Zn mixture. ${ }^{b}$ Using 1 equiv of base. ${ }^{c}$ Putative base.

Using the corresponding lithium-zinc base, there is also a synergy. The base being in this case a mixture of LiTMP and $(\mathrm{TMP})_{2} \mathrm{Zn}$, a reaction pathway where the deprotonation proceeds with LiTMP, and the resultant aryllithium intermediate converts by in situ trapping with (TMP) ${ }_{2} \mathrm{Zn}$ (or ArZnTMP) to the more stabilized arylzinc species was proposed (Scheme $3)$.

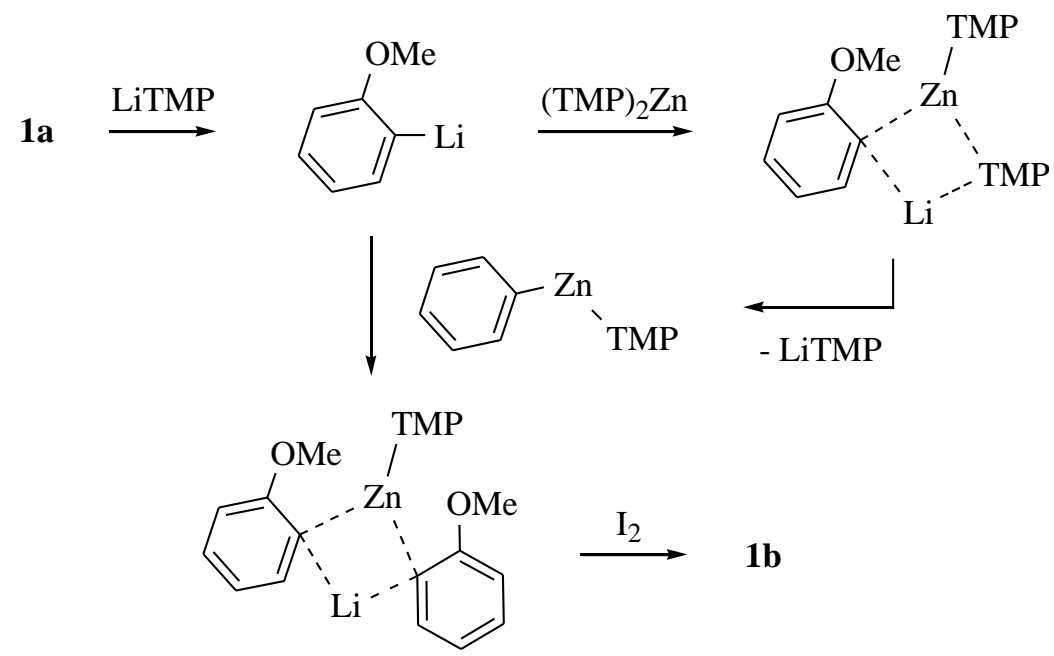

Scheme 3. Proposed reaction pathway for reactions using 1:1 LiTMP and (TMP) ${ }_{2} \mathrm{Zn}$ 


\section{DEPROTONATIVE METALLATION OF FUNCTIONALIZED BENZENES (Table}

2) [20]

The good reactivity of (TMP) ${ }_{3} \mathrm{CdLi}$ being established towards methoxybenzenes $\mathbf{1 a}$ and 2a (entries 1,2), the deprotonation-trapping sequence was applied to benzenes bearing functional groups or heavy halogens. Due to their electrophilic functional group, $\mathrm{N}, \mathrm{N}$ diethylbenzamide (3a) [2a], methyl benzoate (4a) [2a,8a] and benzonitrile (5a) [8a] have scarcely been metallated at room temperature. When possible, for example using (TMP) ${ }_{2} \mathrm{Mg}$ [2a] or ${ }^{t} \mathrm{Bu}_{2} \mathrm{Zn}(\mathrm{TMP}) \mathrm{Li}[8 \mathrm{a}]$ in THF, an excess of base has to be used. The compatibility of the Cd-Li base ( 0.5 equiv) with reactive functional groups allowed the expected iodides $\mathbf{3 b}$, $\mathbf{4 b}$ and $\mathbf{5 b}$ to be formed in good yields (entries 3-5). A ketone function could be tolerated in the reaction, as shown from benzophenone (6a) (entry 6). The accumulation of the metallated derivatives of 4-bromoanisole (7a), 4-iodoanisole [25] (8a), and methyl 4-bromobenzoate (9a) also proved feasible, with a complete regioselectivity for the position far from the halogen atom (entries 7-9).

Table 2. Metallation of functionalized benzenes 1a-9a using (TMP) ${ }_{3} \mathrm{CdLi}$ followed by trapping with $\mathrm{I}_{2}$.

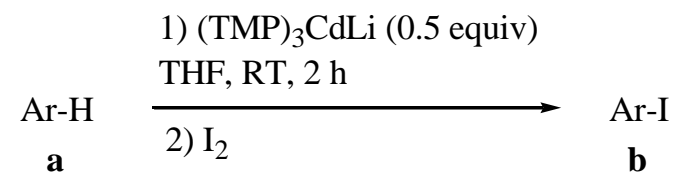

\begin{tabular}{|c|c|c|c|c|c|}
\hline Entry & Substrate (a) & & Product (b) & & Yield $(\%)$ \\
\hline 1 & & 1a & & 1b & $75(84)^{a}$ \\
\hline 2 & $\mathrm{OMe}^{\mathrm{OMe}}$ & $\mathbf{2 a}$ & & $2 \mathrm{~b}$ & 79 \\
\hline
\end{tabular}




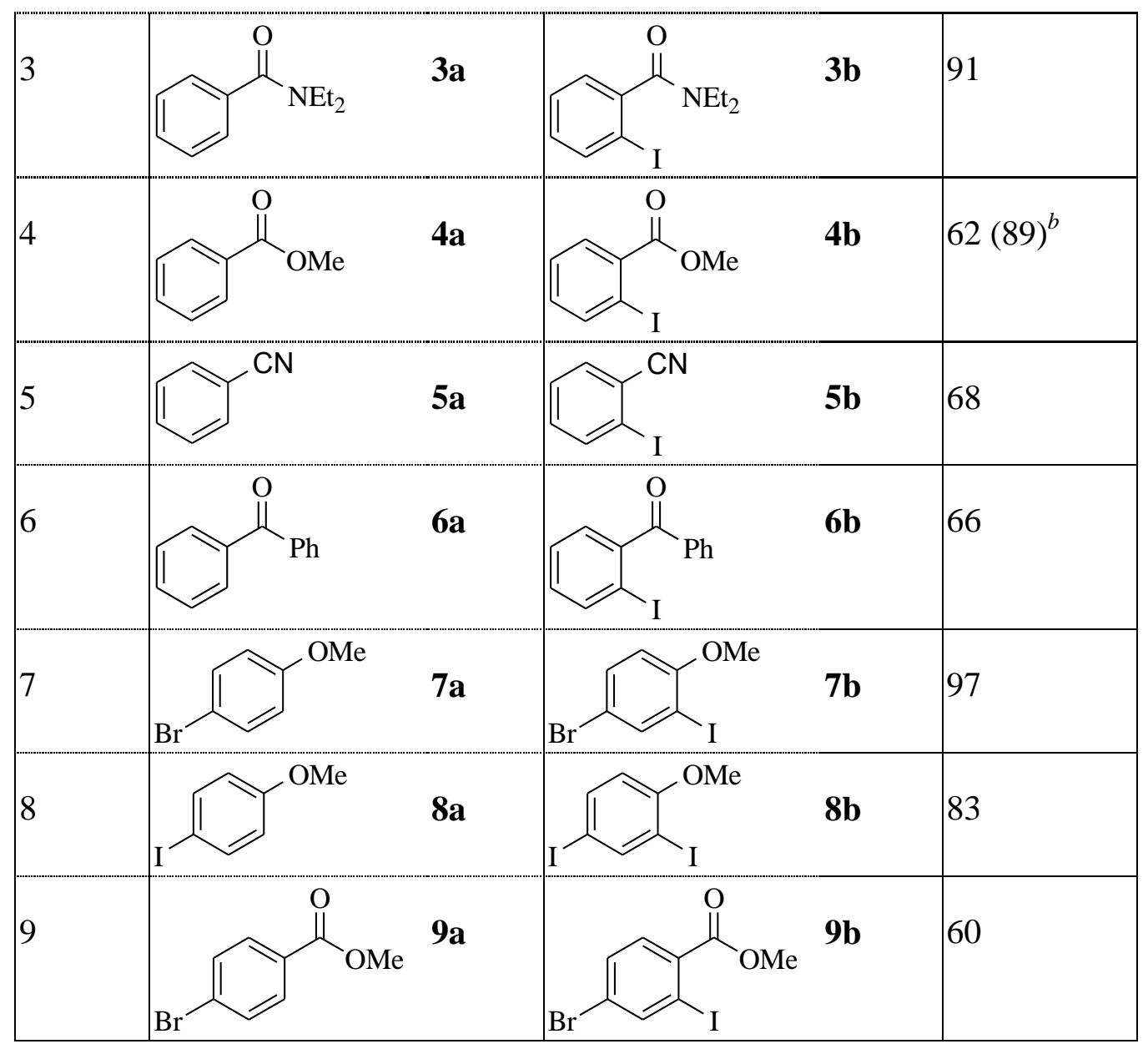

${ }^{a}$ Using the corresponding Li-Zn mixture, LiTMP $(0.5$ equiv $)+(\text { TMP })_{2} \mathrm{Zn}(0.5$ equiv). ${ }^{b}$ Using 1 equiv of (TMP) $)_{3} \mathrm{CdLi}$.

\section{DEPROTONATIVE METALLATION OF FIVE-MEMBERED AROMATIC} HETEROCYCLES (Table 3) [20,26]

Substituted five-membered aromatic heterocycles are structural units present in many natural products and pharmaceutical synthetic intermediates.[27] Deprotonation reactions using lithiated bases have been developed to functionalize them, but this methodology often requires low temperatures and cannot be used when reactive functional groups are present [1e]. Organomagnesium derivatives have been prepared by deprotonation at higher temperatures [28]; nevertheless, because of the limited reactivity of the magnesium amide or diamide used to deprotonate functionalized substrates, an excess has in general to be employed to ensure good yields. In addition, even if the use of mixed lithium-magnesium 
amides seems more promising for this purpose [29], it is hardly extendable to very sensitive substrates.

The cadmiate base proved suitable for the metallation of several five-membered aromatic heterocycles. Benzo[b]thiophene (10a) has previously been magnesiated at room temperature using $\mathrm{TMPMgCl} \cdot \mathrm{LiCl}[30]$, and zincated using the in situ prepared mixture of $(\mathrm{TMP})_{2} \mathrm{Zn}$ and LiTMP [19a]. Its cadmiation was achieved in an excellent yield using the CdLi base, as demonstrated by trapping with iodine (entry 1). Benzo[b]furan (11a) behaved similarly to extend the list of organometallics of these species prepared at room temperature [31] (entry 2). The room temperature zincations of benzothiazole (12a) and benzoxazole (13a) using either $(\mathrm{TMP})_{2} \mathrm{Zn} \cdot 2 \mathrm{MgCl}_{2} \cdot 2 \mathrm{LiCl}[9 \mathrm{a}]$ or the in situ prepared mixture of $(\mathrm{TMP})_{2} \mathrm{Zn}$ and LiTMP [19a] have previously been reported. The cadmiation proceeded quantitatively starting from benzothiazole (12a) whereas a lower 63\% yield was noted in the case of benzoxazole (13a), probably in relation with the in situ opening of the formed 2-metallated species to give 2-isocyanophenolate [29a] (entries 3 and 4). The compatibility of an ester function or a pyrimidine ring with $(\mathrm{TMP})_{3} \mathrm{CdLi}$ in $\mathrm{THF}$ at room temperature has also been recently evidenced with the possible metallation of ethyl thiophene-2-carboxylate (14a) $[32,33]$ and 4methoxythieno[2,3-d]pyrimidine (15a) (entries 5 and 6).

$N$-Boc pyrrole (16a) was converted to the iodide 16b in $68 \%$ yield (entry 7). The diiodide 16c ranking among the by-products detected in the crude, the use of 1 equivalent of base instead of 0.5 equivalent was attempted. Under the same reaction conditions, the dimetallation [34] was favoured, and the diiodide 16c was isolated in $60 \%$ yield (entry 8). The behaviour of other five-membered aromatic heterocycles benefiting from doubly activated positions was studied (entries 9-11). Thiazole (17a) [19a,33] and thiophene (18a) [29b,30,33] underwent monodeprotonation at room temperature when exposed to $\mathrm{DAMgCl}$ [33], $\mathrm{Bu}_{3} \mathrm{MgLi} \cdot \mathrm{TMEDA}[29 \mathrm{~b}]$, or TMPMgCl$\cdot \mathrm{LiCl}$ [30]. When subjected to the in situ prepared 
mixture of (TMP) ${ }_{2} \mathrm{Zn}$ and LiTMP [19a], the dimetallation of thiazole (17a) was not avoided, even using 1/3 equivalent of base; using 1 equivalent of (TMP) ${ }_{3} \mathrm{CdLi}$, the diiodide $17 \mathrm{c}$ was isolated in $50 \%$ yield. Better yields of 74 and $81 \%$ were obtained for the thiophene diiodides 18c and 19c under the same reaction conditions. Furan is amenable to magnesiation at room temperature using either $\mathrm{Bu}_{4} \mathrm{MgLi}_{2}$ [35] or $\mathrm{TMPMgCl} \cdot \mathrm{LiCl}$ [30]. Using (TMP) ${ }_{3} \mathrm{CdLi}$, its monocadmiation occurred but attempts to dimetallate it were disappointing, in contrast to what has recently been observed using stronger [(TMEDA) $\left.\cdot \mathrm{Na}\left(\mathrm{CH}_{2} \mathrm{SiMe}_{3}\right)(\mathrm{TMP}) \mathrm{Mg}(\mathrm{TMP})\right]$ [36].

Table 3. Metallation of five-membered aromatic heterocycles 10a-19a using (TMP) ${ }_{3} \mathrm{CdLi}$ followed by trapping with $\mathrm{I}_{2}$.

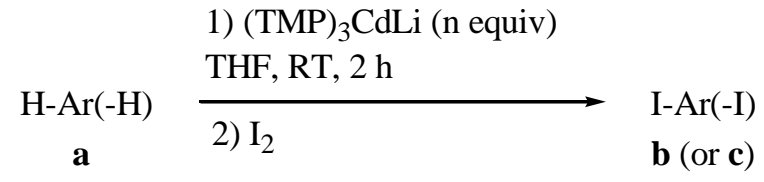

\begin{tabular}{|c|c|c|c|c|c|c|}
\hline Entry & $\mathrm{n}$ & Substrate (a) & & Product (b or $\mathbf{c})$ & & Yield (\%) \\
\hline 1 & 0.5 & & $10 \mathbf{a}$ & & $10 b$ & $97(73)^{a}$ \\
\hline 2 & 0.5 & & $11 a$ & & $11 b$ & $84(69)^{a}$ \\
\hline 3 & 0.5 & & $12 \mathbf{a}$ & & $12 \mathrm{~b}$ & $97(52)^{a}$ \\
\hline 4 & 0.5 & & 13a & & $13 b$ & $63(57)^{a}$ \\
\hline 5 & 0.5 & & $14 a$ & & $14 b$ & 77 \\
\hline 6 & 0.5 & & $15 \mathbf{a}$ & & $15 b$ & 76 \\
\hline
\end{tabular}




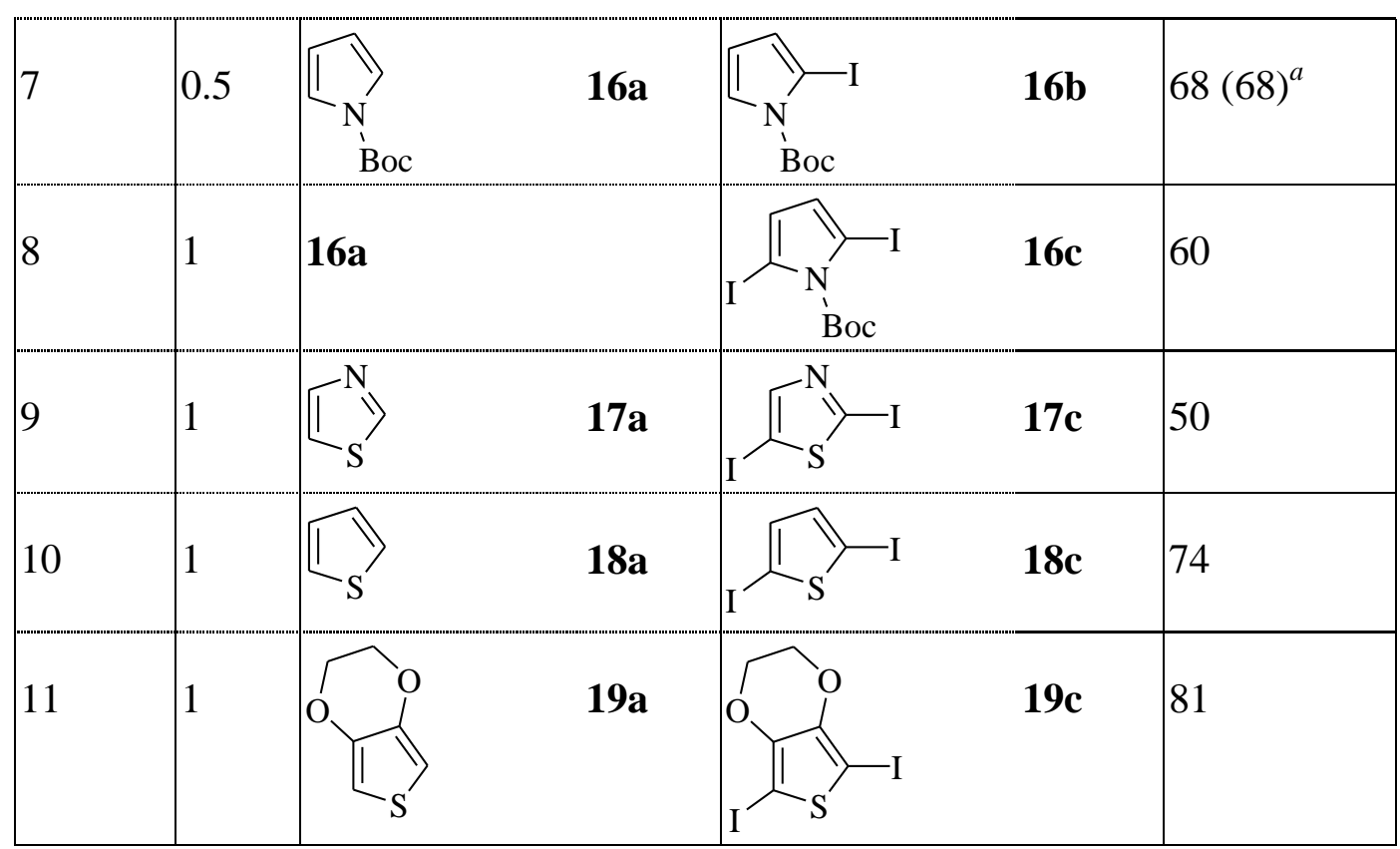

${ }^{a}$ Using the corresponding Li-Zn mixture, LiTMP $(0.5$ equiv $)+(\mathrm{TMP})_{2} \mathrm{Zn}(0.5$ equiv).

\section{DEPROTONATIVE METALLATION OF SUBSTITUTED PYRIDINES}

Extensive efforts on synthesis methodologies have been devoted to pyridine compounds, due to their presence in numerous natural products and pharmaceuticals, as well as in building blocks for various applications such as material science and supramolecular chemistry [27].

\section{1) Halopyridines (Table 4) [20b,37]}

Due to easy elimination of metal halide giving pyridyne [38], deproto-metallation of chloropyridines can hardly be achieved at room temperature [38,39]. Hindered lithium dialkylamides promote a metallation at the 3 or 4 position, adjacent to the halogen of 2chloro, 3-chloro, 4-chloro, and 2,3-dichloropyridine [40]. 3,5-Dichloropyridine undergoes lithiation at the position flanked by the two halogen atoms [40]. 2,6-Dichloropyridine tends to form mixtures of 3- and 4-substituted derivatives when treated with LiDA or sec-butyllithium in THF at low temperatures, but the use of phenyllithium as well as extended contact times 
with LiDA favour the 3-substituted products [40]. 2,5-Dichloropyridine can be lithiated either next to the nitrogen using tert-butyllithium or at the 4 position using TMEDA-activated butyllithium [40].

The use of lithium magnesiates has been attempted at $-10^{\circ} \mathrm{C}$, but resulted in mixtures due to problems of regio- and chemoselectivity [41]. Chemoselectivity was present upon reaction with TMP-cadmiate, but not regioselectivity. Starting from 2-chloropyridine (20a), using 0.5 equivalent of (TMP) ${ }_{3} \mathrm{CdLi}$ resulted in the major formation of the 3 -iodo and the 6iodo derivatives 20b1 and 20b2. By increasing the amount of base to 1 equivalent, an important formation of diiodides was observed, the 2,6-diiodo derivative 20c1 being the most important (entry 1). From 3-chloropyridine (21a), it was possible to use either 0.5 equivalent of base to provide the 2-iodo derivative $\mathbf{2 1 b 1}$ in $50 \%$ yield, or 1 equivalent of base to generate the 2,4-diiodo derivative 21c1 in $69 \%$ yield (entry 2).

It is interesting to note the possible deprotonation next to the nitrogen atom, as previously reported with BuLi-LiDMAE (DMAE = 2-dimethylaminoethoxide) [42]. When both the 2 and 6 positions of the pyridine ring are substituted, for example with 2,6dichloropyridine (22a) [43], the result of the cadmiate-mediated reaction more looked like what is observed using classical lithium bases, with a mixture of 3-iodo and 4-iodo derivatives 22b1,22b2. Concomitant formation of the diiodides $22 \mathrm{c} 1$ and $22 \mathrm{c} 2$ could be in relation with the combined acidifying effects of the chloro groups (entry 3). By increasing the size of the substituents, the abstraction of the hydrogen at the less hindered position was favoured. Indeed, starting from 2,6-dibromopyridine (23a) [43], the 4-iodo derivative was obtained in $71 \%$ yield (entry 4$)$.

Table 4. Metallation of halopyridines 20a-23a using (TMP) $)_{3} \mathrm{CdLi}$ followed by trapping with $\mathrm{I}_{2}$. 


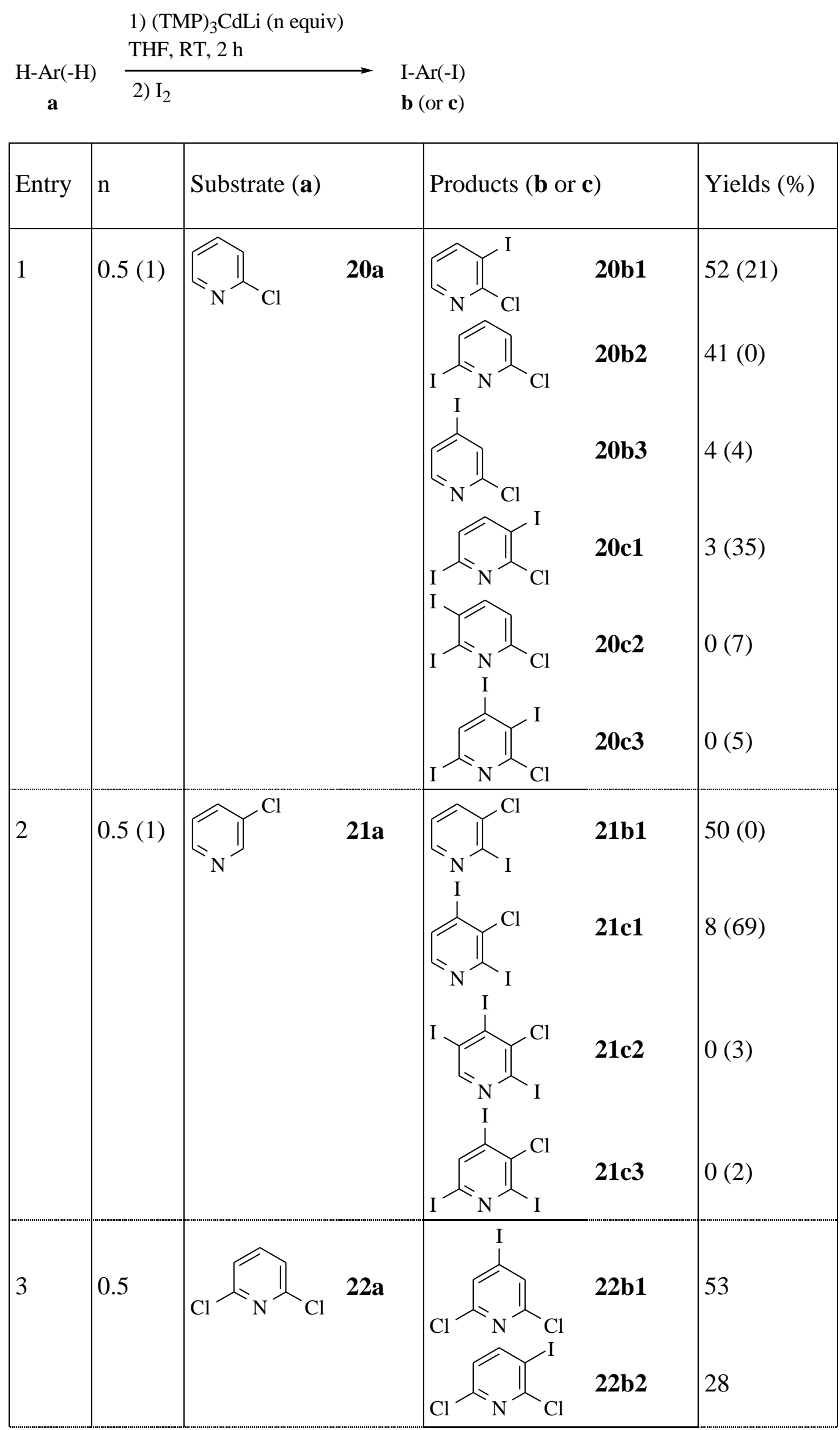




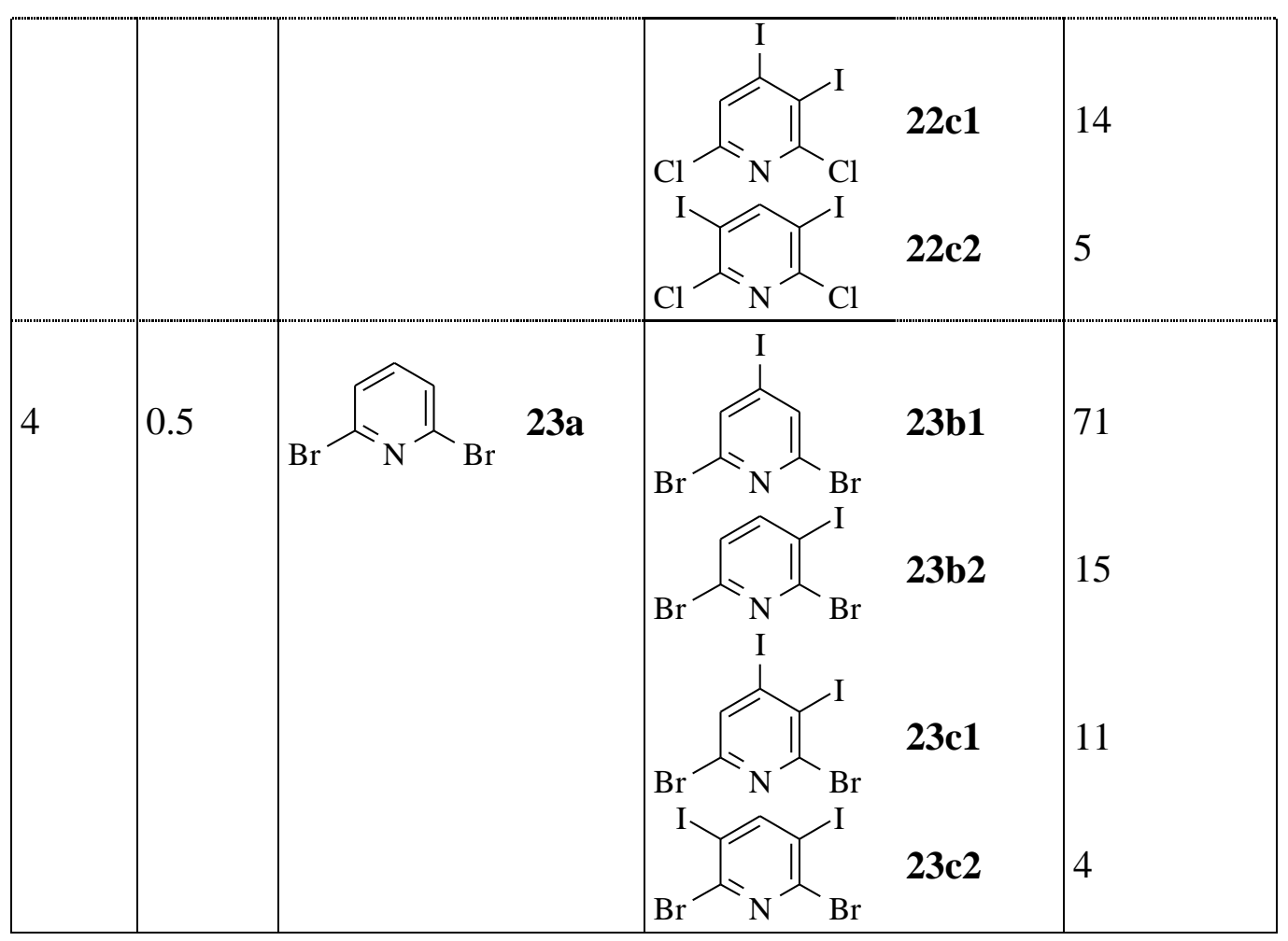

2) Cyanopyridines (Table 5) [26a]

Due to their electrophilic functional group and to their ring prone to nucleophilic attacks, cyanopyridines have never been metallated at room temperature. Reactions using cyano as a group to direct ortho-lithiation have been reported in the benzene series from 1982 [44], but the first example in the pyridine series only appeared 20 years later. Larock and coworkers showed in 2002 that it was possible to lithiate 3-cyanopyridine using LiTMP in THF at $-78^{\circ} \mathrm{C}$. This result was evidenced by subsequent trapping with iodine to afford a $1: 1$ mixture of the 2- and 4-iodo compounds in a 50\% total yield [45]. Rault and co-workers achieved in 2005 the regioselective functionalization of the other cyanopyridine isomers using 2 equivalents of the same hindered lithium amide in THF at $-80^{\circ} \mathrm{C}$ for $0.75 \mathrm{~h}$ [46].

The deprotonation of cyanopyridines (24a-26a) was attempted using (TMP) $)_{3} \mathrm{CdLi}$ in THF. Conducting the reaction from 2-cyanopyridine (24a) using 0.5 equivalent of base at $0^{\circ} \mathrm{C}$ for $2 \mathrm{~h}$ resulted, after quenching with iodine, in the formation of a mixture from which the main compound, 2-cyano-3-iodopyridine (24b), could be isolated in 39\% yield. When the 
reaction was carried out at room temperature, the iodide $\mathbf{2 4 b}$ was formed in $30 \%$ yield, due to the more important formation of side products (entry 1). By using 1 equivalent of base at room temperature, the di- and triiodide $\mathbf{2 4 c 1 , 2 4 c 2}$ were obtained in 28 and $20 \%$ yield, respectively (entry 2). If the formation of a diiodinated compound can be rationalized as the result of a dimetallation, (TMP) $)_{3} \mathrm{CdLi}$ being able to dideprotonate substrates such as thiazole, $N$-Boc pyrrole and thiophenes [20], the triiodide $\mathbf{2 4 c 2}$ could rather result from a remetallation of $\mathbf{2 4 c 1}$ during the trapping step with iodine.

The reaction from 4-cyanopyridine (25a) was attempted using 0.5 equivalent of base at $0^{\circ} \mathrm{C}$ for $2 \mathrm{~h}$; subsequent trapping with iodine afforded a mixture of 4-cyano-3-iodo- and 4cyano-3,5-diodopyridine (25b1 and 25c1) in 30 and 20\% yield, respectively (entry 3). By performing the reaction at room temperature, the diiodide $\mathbf{2 5 c 1}$ was not observed, but a 72:28 ratio of 4-cyano-3-iodopyridine (25b1) and isomeric 4-cyano-2-iodopyridine (25b2) was obtained instead, and the iodides were isolated in 44 and $10 \%$ yield, respectively (entry 4 ). Surprisingly, carrying out the reaction with 1 equivalent of base resulted in the formation of the diiodide $\mathbf{2 5 c 2}$ under the same conditions (entry 5).

The result obtained with 3-cyanopyridine (26a) proved more promising. Indeed, when exposed to 0.5 equivalent of base at room temperature for $2 \mathrm{~h}$, this substrate was regioselectively metallated at the 2 position. This was demonstrated by subsequent interception with iodine to afford the derivative $\mathbf{2 6 b}$ in $61 \%$ yield (entry 6). This regioselectivity is different to that previously documented by other teams using LiTMP in THF at low temperatures; indeed, by using the lithium amide, the metallation takes place unregioselectively at the positions adjacent to the cyano group $[45,46 a]$. Such a result could be partly explained by the presence of a different directing group for the metallation using LiTMP than for that using (TMP) ${ }_{3} \mathrm{CdLi}$; whereas a first equivalent of LiTMP adds to the 
cyano group in the study performed by Rault and co-workers, it does not seem to be the case with (TMP) $)_{3} \mathrm{CdLi}$ (Scheme 4).

Table 5. Metallation of cyanopyridines (24a-26a) using (TMP) ${ }_{3} \mathrm{CdLi}$ followed by trapping with $\mathrm{I}_{2}$.

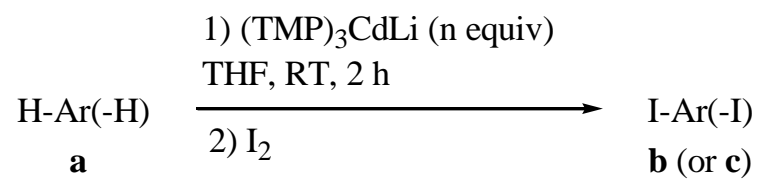

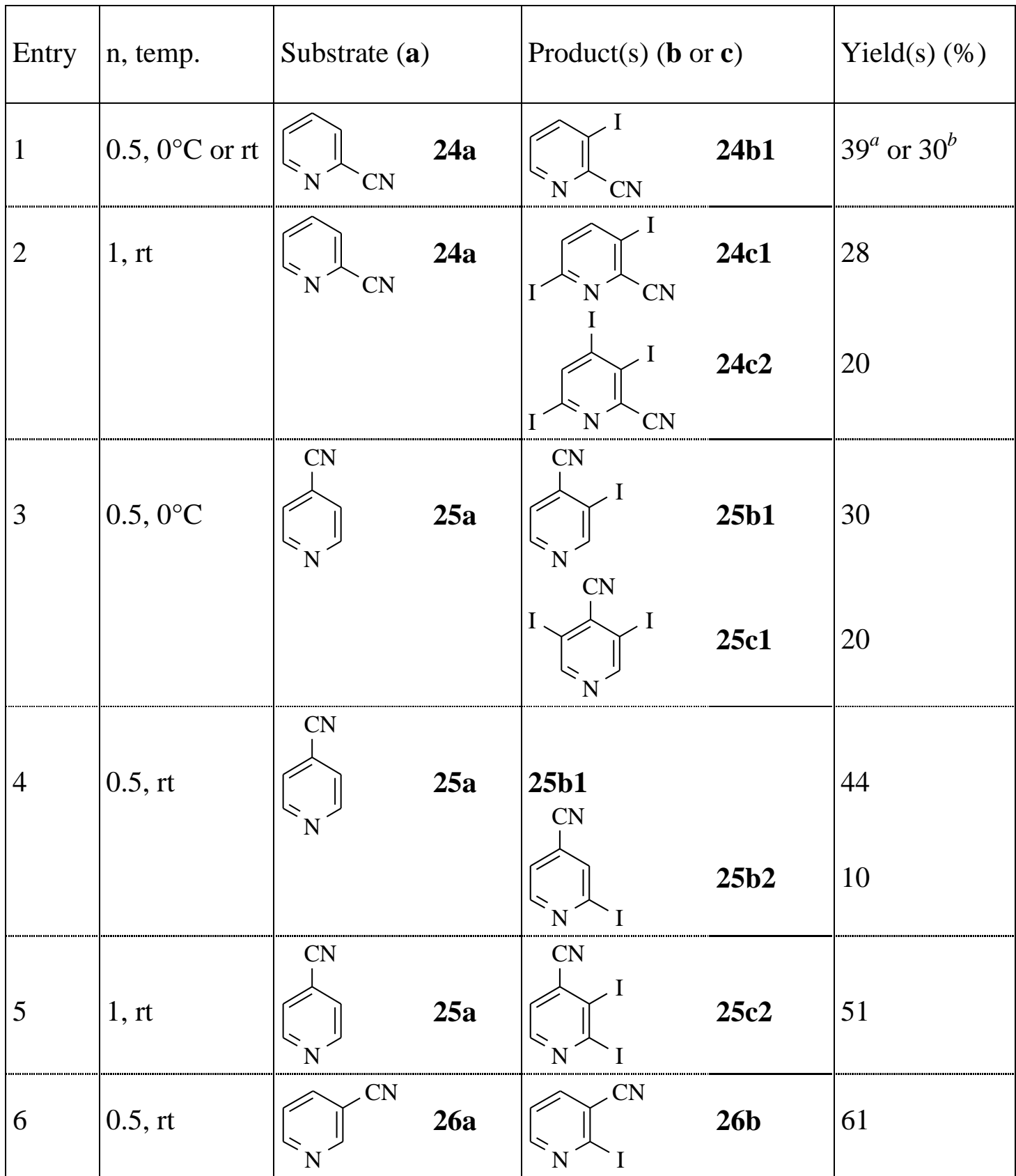


a Other compounds including 2-cyano-3,4-diiodopyridine and 2-cyano-3,6diiodopyridine were identified in the crude. ${ }^{b}$ Other compounds including 2-cyano-6iodopyridine and 2-cyano-3,6-diiodopyridine were identified in the crude.

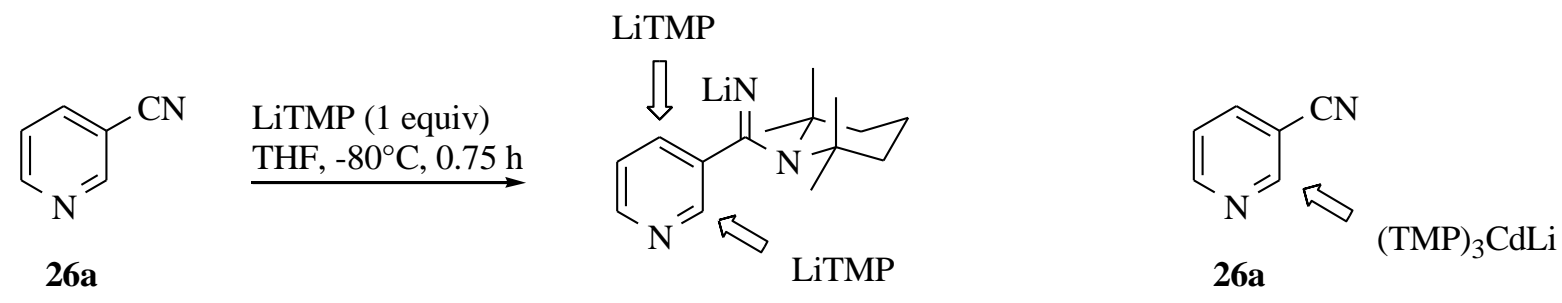

Scheme 4. 3-Cyanopyridine (26a): comparisons of the species before ring deprotonation using LiTMP and (TMP) ${ }_{3} \mathrm{CdLi}$

\section{3) Pyridine esters (Table 6) [26a]}

Deprotonation of ethyl pyridinecarboxylates is also a difficult challenge due to easy nucleophilic attacks on their ring. In 2007, Knochel and co-workers reported the magnesiation of ethyl isonicotinate using (TMP) $)_{2} \mathrm{Mg} \cdot 2 \mathrm{LiCl}$ in $\mathrm{THF}$ at $-40^{\circ} \mathrm{C}$ for $12 \mathrm{~h}$ to give, after trapping with iodine, the corresponding 3-iodo derivative in $66 \%$ yield [47].

The deprotonation of the different pyridine or pyridazine esters $27 \mathbf{a}-30 a$ was attempted using (TMP) $)_{3} \mathrm{CdLi}$ in THF at room temperature for $2 \mathrm{~h}$, and the metallated species intercepted with iodine. Conducting the reaction from ethyl picolinate (27a) using 0.5 equivalent of base resulted in the major formation of the 3 -iodo derivative $\mathbf{2 7} \mathbf{b}$, which was isolated in 58\% yield (entry 1). Ethyl isonicotinate (28a) similarly furnished the 3-iodo compound $\mathbf{2 8 b}$, and the yield of $65 \%$ could be slightly improved to $72 \%$ using 1 equivalent of base (entry 2). Surprisingly, methyl pyridazine-4-carboxylate (29a) behaved differently when submitted to 0.5 equivalent of base, with a complex mixture of mono- and diiodides formed (entry 3). When treated under the same conditions, ethyl nicotinate (30a) allowed the synthesis of the 4-iodo derivative $\mathbf{3 0 b}$ (entry 4). The latter could not be isolated due to its unstability over silica gel, but was identified by NMR. It was involved without purification in 
a known copper-catalyzed reaction [48] with pyrazole to provide the expected derivative 30d in a two steps $38 \%$ yield (Scheme 5).

When methyl pyridine-2,6-dicarboxylate (31a) was involved in the deprotonationtrapping sequence using 0.5 equivalent of (TMP) $)_{3} \mathrm{CdLi}$, the 3 -iodo, 4-iodo and 3,4-diiodo derivatives 31b1, 31b2 and 31c1 were obtained in a 63:28:9 ratio. Whereas the main compounds $31 \mathrm{~b} 1$ and $31 \mathbf{b 2}$ could be isolated from the mixture in 35 and $3 \%$ yield, respectively, methyl 3,4-diiodopyridine-2,6-dicarboxylate (31c1) was only identified from the NMR spectra of the crude. Turning to 1 equivalent of base resulted in the formation of a fourth derivative, methyl 3,5-diiodopyridine-2,6-carboxylate (31c2), together with the previous iodides. It could be isolated from the 22:25:4:49 mixture of the 3-iodo, 4-iodo, 3,4diiodo and 3,5-diiodo compounds in a modest $14 \%$ yield.

Table 6. Metallation of pyridine or pyridazine esters 27a-31a using (TMP) ${ }_{3} \mathrm{CdLi}$ followed by trapping with $\mathrm{I}_{2}$.

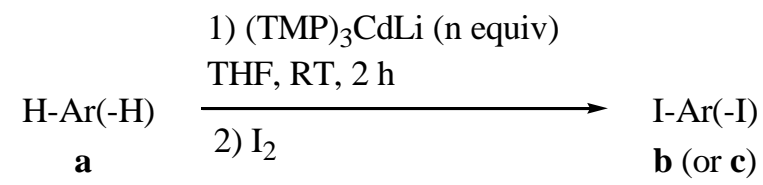

\begin{tabular}{|l|l|l|ll|l|}
\hline Entry & $\mathrm{n}$ & Substrate (a) & Yields (\%), \\
(Conversions (\%))
\end{tabular}




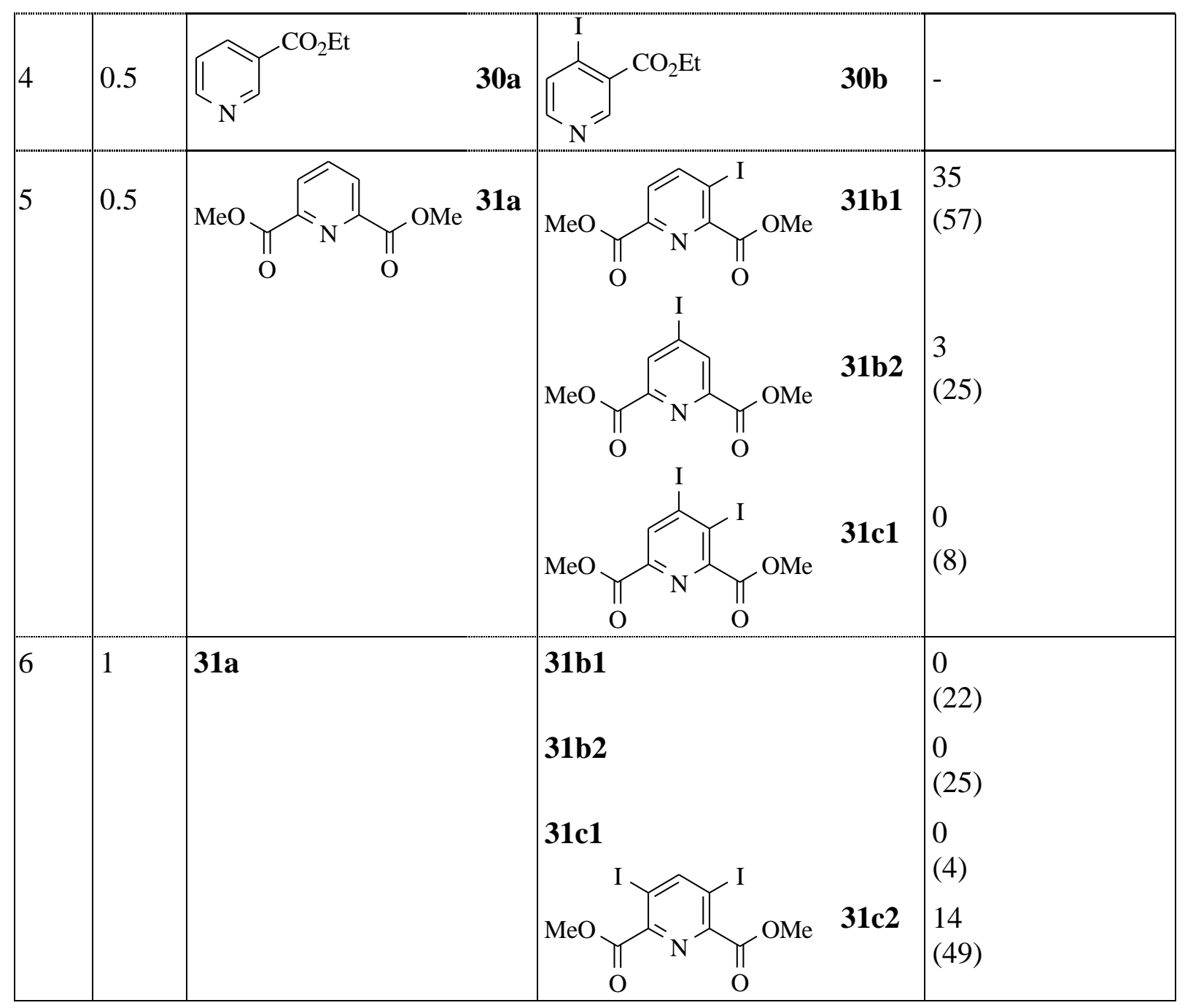

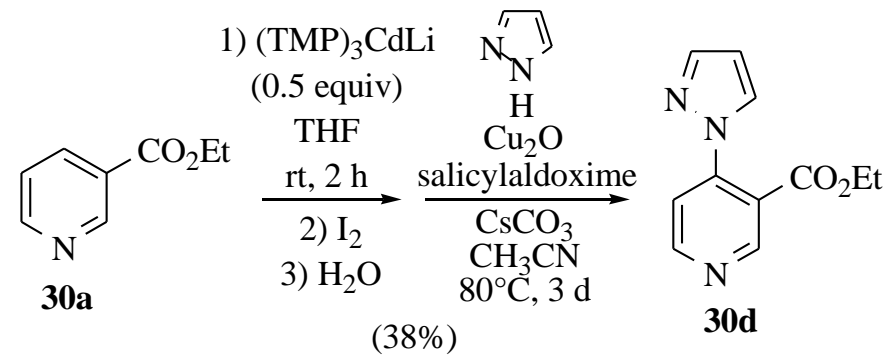

Scheme 5. Synthesis of ethyl 4-(pyrazol-1-yl)nicotinate (30d)

\section{4) [1,2,3]Triazolo[1,5-a]pyridines (Table 7) [49]}

Among the methods used to functionalize [1,2,3]triazolo[1,5-a]pyridines [50], deprotonative metallation reactions using lithium bases have been developed, but only proved efficient in the absence of reactive functional groups, and provided that very low reaction 
temperatures are used. First studies about the lithiation of $[1,2,3]$ triazolo $[1,5-a]$ pyridine $(\mathbf{3 2 a})$ have been reported from 1980, and showed butyllithium and LiDA are suitable for a regioselective metallation at the 7 position when used in ethereal solvents (the best yields being obtained in THF) provided that the reaction temperature is kept below $-40^{\circ} \mathrm{C}$ [51]. Similar reaction conditions can be used for 3-methyl and 3-phenyl derivatives 33a and 34a [51]. Above this temperature, the corresponding 7,7'-dimers form [52]. Metallation yields were improved in 1987 by using butyllithium in toluene at $-40^{\circ} \mathrm{C}$ [53].

The use of (TMP) ${ }_{3} \mathrm{CdLi}$ was attempted in order to avoid butyllithium which hardly tolerates functional groups, and requires low temperatures which can be difficult to realize on an industrial scale. When substrates 32a and 34a were successively treated by in situ prepared $(\mathrm{TMP})_{3} \mathrm{CdLi}(0.4$ equiv) in THF at room temperature for $2 \mathrm{~h}$, and iodine, the expected iodides 32b and 34b were provided in 71 to $72 \%$ yields (entries 1 and 3 ). The iodide 33b was obtained similarly from 33a in $76 \%$ yield (entry 2 ), but using 1 equiv of (TMP) ${ }_{3} \mathrm{CdLi}$. The direct cadmiation of more elaborated substrates such as 3 -cyano-[1,2,3]triazolo[ $[1,5-a]$ pyridine (35a), for which the deproto-lithiation only gives a complex mixture of derivatives [54], was studied. When submitted successively to the mixed lithium-cadmium base and iodine under the conditions used for 32a and 34a, the expected iodide $\mathbf{3 5 b}$ was isolated in a satisfying $65 \%$ yield (entry 4). 3-(2-Pyridyl)-[1,2,3]triazolo[1,5-a]pyridine (36a) and 3-(2-thienyl)$[1,2,3]$ triazolo[1,5- $a]$ pyridine (37a) have previously been metallated using LiDA in THF [55]. The protocole here developed also allowed the iodides $\mathbf{3 6} \mathbf{\prime} \mathbf{b}$ and $\mathbf{3 7} \mathbf{b}$ to be obtained (entries 5,6). The formation of $\mathbf{3 6} \mathbf{\prime} \mathbf{b}$ instead of expected $\mathbf{3 6} \mathbf{b}$ could be rationalized as previously reported [55] (Scheme 6).

Table 7. Metallation of $[1,2,3]$ triazolo[1,5-a]pyridines (32a-37a) using (TMP) ${ }_{3} \mathrm{CdLi}$ followed by trapping with $\mathrm{I}_{2}$. 
1) $(\mathrm{TMP})_{3} \mathrm{CdLi}$ ( $\mathrm{n}$ equiv)

THF, rt, $2 \mathrm{~h}$

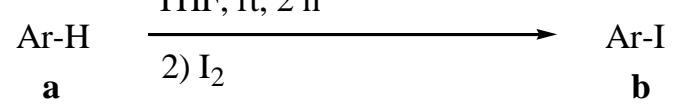

\begin{tabular}{|c|c|c|c|c|c|c|}
\hline Entry & $\mathrm{n}$ & Substrate (a) & & Product (b) & & Yield (\%) \\
\hline 1 & 0.4 & $\mathrm{~N}=\mathrm{N}$ & 32a & $\mathrm{N}=\mathrm{N}$ & 32b & 72 \\
\hline 2 & 1 & & $33 \mathbf{a}$ & & 33b & $76(23)^{a}$ \\
\hline 3 & 0.4 & & $34 a$ & $N=N$ & $34 b$ & 71 \\
\hline 4 & 0.4 & $\mathrm{~N}=\mathrm{N}$ & $35 \mathbf{a}$ & & $35 b$ & 65 \\
\hline 5 & 0.4 & $\mathrm{~N}=\mathrm{N}$ & 36a & & $36 b \rightarrow 36^{\prime} b$ & $73(49)^{b}$ \\
\hline 6 & 0.4 & $\mathrm{~N}=\mathrm{N}$ & $37 \mathbf{a}$ & $N=N$ & $37 b$ & 38 \\
\hline
\end{tabular}

${ }^{a}$ Using BuLi, THF, $-40^{\circ} \mathrm{C} .{ }^{b}$ Using LiDA, THF, $-40^{\circ} \mathrm{C}$.

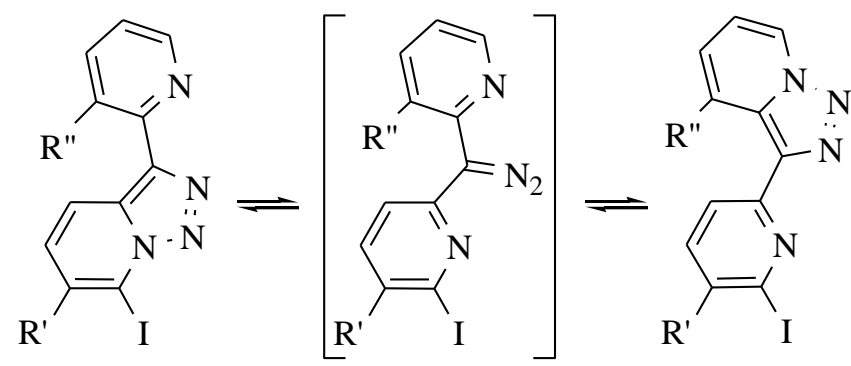

36b: $\mathrm{R}^{\prime}=\mathrm{R}^{\prime \prime}=\mathrm{H}$

36c: $\mathrm{R}^{\prime}=\mathrm{H}, \mathrm{R}^{\prime \prime}=\mathrm{I}$

36'b: $\mathrm{R}^{\prime}=\mathrm{R}^{\prime \prime}=\mathrm{H}$

36'c: $\mathrm{R}^{\prime}=\mathrm{H}, \mathrm{R} "=\mathrm{I}$

36d: $\mathrm{R}^{\prime}=\mathrm{R}^{\prime \prime}=\mathrm{I}$

36'd: $\mathrm{R}^{\prime}=\mathrm{R}^{\prime \prime}=\mathrm{I}$

Scheme 6. Isomerization of 7-iodo-3-(2-pyridyl)-[1,2,3]triazolo[1,5-a]pyridines 36b-d 
The access to diiodo derivatives of $[1,2,3]$ triazolo[1,5- $a]$ pyridines proved possible using 1 equivalent of base. Starting from 32a, the 3,7-diiodo derivative 32c was isolated in 66\% yield (Scheme 7). Unexpectedly, a mixture of the diiodide 36'c and the triiodide 36'd, from which the latter was isolated in 30\% yield, was obtained from 36a using the same protocole. The iodides 36'c and 36'd probably result from an isomerization of the compounds 36c and 36d, as described above (Scheme 6). The precursor 36c could be formed by dideprotonation at both 7 (the more activated position of $[1,2,3]$ triazolo[1,5-a]pyridine) and 3' (induced by the neighboring triazole ring) positions [56]. The triiodide $\mathbf{3 6 d}$ could be generated by metallation of 36c during the trapping with iodine (excess of base). The formation of the diiodide $37 \mathbf{c}$ is less unexpected, and logically results from a dideprotonation at the more activated positions of the $[1,2,3]$ triazolo[1,5-a]pyridine and thiophene rings (Scheme 7).

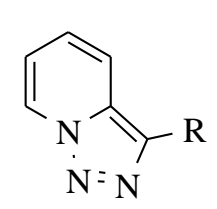

32a: $\mathrm{R}=\mathrm{H}$

36a: $\mathrm{R}=2$-pyridyl

37a: $\mathrm{R}=2$-thienyl
1) $(\mathrm{TMP})_{3} \mathrm{CdLi}$ (1 equiv) THF, rt, 2 h

2) $\mathrm{I}_{2}$

3) $\mathrm{H}_{2} \mathrm{O}$<smiles>Ic1nnn2c(I)cccc12</smiles>

32c: $66 \%$<smiles>[R]c1ccc(-c2nncn2-c2ncccc2I)nc1I</smiles>

36'c $\left(R^{\prime}=H\right) ; \mathbf{3 6}^{\prime} \mathbf{d}\left(\mathrm{R}^{\prime}=\mathrm{I}\right): 30 \%$

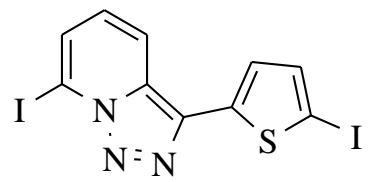

37c: $75 \%$

Scheme 7. Polydeprotonation of 32a, 36a and 37a using (TMP) ${ }_{3} \mathrm{CdLi}$ (1 equiv) followed by trapping with $\mathrm{I}_{2}$

\section{DEPROTONATIVE METALLATION OF DIAZINES}

The preparation of functionalized diazines is an important synthetic goal because of the multiple applications of these molecules [27]. Metallation of diazines is a difficult challenge due to very facile nucleophilic addition reactions in relation with the low LUMO energy levels of these substrates. Recourse to hindered dialkylamides such as LiDA and 
LiTMP allows numerous substituted diazines to be deprotonated [38,57]. Without substituent, reactions are less obvious. Metallation of pyrazine and pyridazine is possible with an excess of LiTMP and very short reaction times at very low temperatures, while metallation of pyrimidine can only be accomplished using the in situ trapping technique [58]. Kondo described in 2003 the unprecedented regioselective functionalization of pyridazine and pyrimidine at positions 4 and 5 , respectively, using hindered phosphazene $t \mathrm{Bu}-\mathrm{P} 4$ base and $\mathrm{ZnI}_{2}$ as additive in toluene, and in the presence of a carbonylated compound as electrophile [59]. Knochel has reported since 2006 the use of mixed lithium-magnesium amides such as (TMP) $\mathrm{MgCl} \cdot \mathrm{LiCl}$ for the deprotonation of diazines $[30,60]$ the method is powerful, but it still requires low temperatures, and has not been used for unsubstituted substrates.

The good chemoselectivity observed during the Cd-Li base-mediated deprotonations of pyridines led to its use for the metallation of diazines.

\section{1) Bare diazines (Table 8) [61]}

Attempts to metallate pyridazine, pyrimidine or pyrazine indicate that the $\mathrm{Cd}-\mathrm{Li}$ base is suitable for an efficient reaction in THF at room temperature. Indeed, subsequent trapping with iodine after $2 \mathrm{~h}$ afforded substituted derivatives in satisfying yields. Whereas 4iodopyrimidine (38b) was regioselectively formed from pyrimidine (38a) using 0.5 equivalent of base, a mixture of 3- and 4-iodopyridazine (39b1 and 39b2) was obtained from pyridazine (39a) using 1 equivalent of base in a 60/40 ratio. Iodopyrazine (40b) was isolated in 63\% yield using $\mathrm{CdCl}_{2}$.TMEDA (0.33 equiv) and LiTMP (1 equiv). If the amounts of $\mathrm{CdCl}_{2} \cdot$ TMEDA and LiTMP go into 0.5 equivalent and 1.5 equivalent, respectively, 2,5diiodopyrazine (40c) concomitantly forms (20\% yield) to the detriment of iodopyrazine (40b) (59\% yield). 
The use of 1 equivalent of $\mathrm{CdCl}_{2}$.TMEDA and 3 equivalents of LiTMP was attempted to deprotonate pyrazine (40a). Under the same reactions conditions, the diiodide 40c was isolated in $58 \%$ yield when the reaction was performed on a 2 mmol scale. The protocole could be successfully transposed to a $25 \mathrm{mmol}$ scale, albeit providing compound $40 \mathrm{c}$ in a lower $40 \%$ yield.

Table 8. Metallation of bare diazines (38a-40a) using (TMP) ${ }_{3} \mathrm{CdLi}$ followed by trapping with $\mathrm{I}_{2}$.

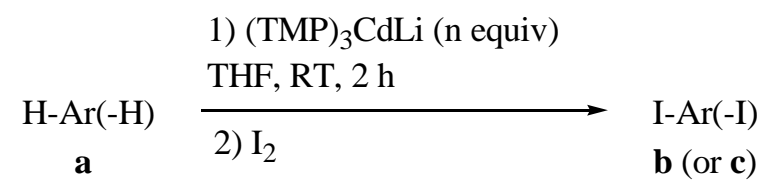

\begin{tabular}{|c|c|c|c|c|}
\hline Entry & $\mathrm{n}$ & Substrate (a) & Product (b or $\mathbf{c})$ & Yield (\%) \\
\hline 1 & 0.5 & $38 \mathbf{a}$ & $38 b$ & $71(57)^{a}$ \\
\hline 2 & 1 & 39a & 39b1 & $55(66)^{b}$ \\
\hline & & & $39 \mathrm{~b} 2$ & 41 \\
\hline 3 & 0.33 & $40 \mathbf{a}$ & $40 \mathrm{~b}$ & 63 \\
\hline 4 & 0.5 & $40 a$ & $\begin{array}{l}\text { 40b } \\
\mathrm{I}_{Y}\end{array}$ & $\begin{array}{l}59(59)^{a} \\
20\end{array}$ \\
\hline 5 & 1 & $40 a$ & $40 c$ & $58(40)^{c}$ \\
\hline
\end{tabular}

${ }^{a}$ Using the corresponding Li-Zn base, LiTMP ( 0.5 equiv) + (TMP) $)_{2} \mathrm{Zn}$ (0.5 equiv). ${ }^{b}$ Using the corresponding Li-Zn base, LiTMP $(0.5$ equiv $)+(\mathrm{TMP})_{2} \mathrm{Zn}(0.5$ equiv $)$, at reflux in THF containing 5 equiv of TMEDA. ${ }^{c}$ On a 25 -mmol scale. 
The metallation of all the unsubstituted diazines could also be performed at room temperature or more in THF using the mixture of (TMP) ${ }_{2} \mathrm{Zn}$ and LiTMP ( 0.5 equiv each) [19c], but in lower yields probably in relation with the presence of free LiTMP in the reaction mixture.

To our knowledge, the synthesis of 2,5-diiodopyrazine (40c) has never been reported by other methods. Similar compounds such as 2-bromo-5-iodopyrazine [62] and 2,5dibromopyrazine [63] have previously been prepared by diazotization of 5bromopyrazinamine ( $41 \%$ and $66 \%$ yield, respectively), the latter being accessible by bromination of pyrazinamine (75\% yield) [64]. Such compounds could find applications as substrates for the synthesis of molecules endowed with biological [65] or photophysical [66] properties.

\section{2) Substituted diazines (Table 9) [20b,26a]}

Whereas LiTMP has to be used at $-75^{\circ} \mathrm{C}$ in order to avoid the formation of a dimer [57], the mixed base could be employed at room temperature for the cadmiation of methoxypyrazine (41a), and the metallated heterocycle subsequently intercepted by iodine (entry 1). The situation became more complex with 2,4-dimethoxypyrimidine (42a) since the 5 position can be attacked using LiTMP at $-75^{\circ} \mathrm{C}$ [57], and the 6 position using $\mathrm{TMPMgCl} \cdot \mathrm{LiCl}$ at room temperature [67]. The $(\mathrm{TMP})_{3} \mathrm{CdLi}$-promoted reaction took place in a satisfying yield using the $\mathrm{Cd}-\mathrm{Li}$ base, but with a complete lack of regioselectivity, leading to the 5- and 6-iodo derivatives $\mathbf{4 2 b 1}$ and $\mathbf{4 2 b 2}$ in a 43:57 ratio and 84\% overall yield (entry 2). These conditions were extended to cyanopyrazine (43a) for which metallation mainly took place at the position next to the cyano group to furnish the iodide $\mathbf{4 3 b}$ in $43 \%$ yield (entry 3 ). 
Table 9. Metallation of substituted diazines 41a-43a using (TMP) ${ }_{3} \mathrm{CdLi}$ followed by trapping with $\mathrm{I}_{2}$.

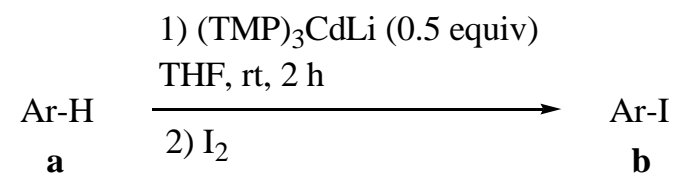

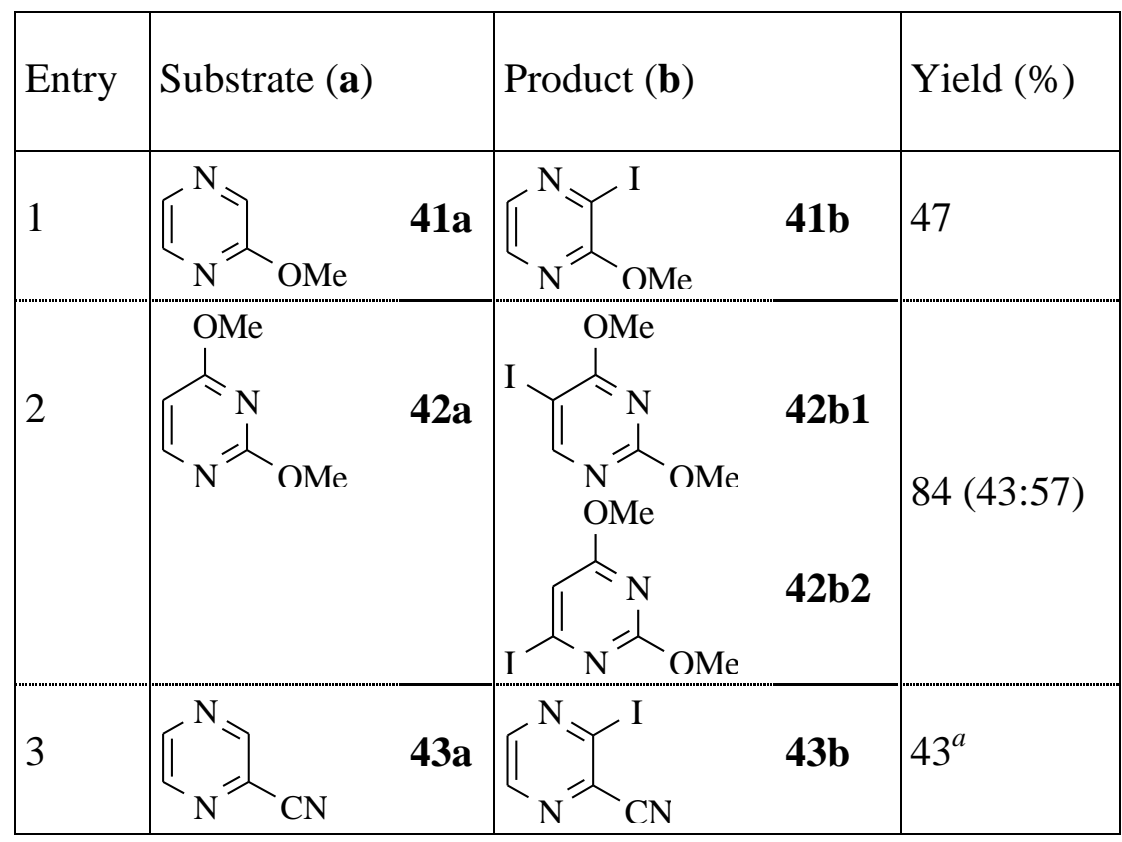

${ }^{a}$ A mixture of $\mathbf{4 3 b}$ and an unidentified diiodide was obtained in a $75: 25$ ratio.

\section{DEPROTONATIVE METALLATION OF FERROCENES (Table 10) [68]}

Ferrocene available compounds have been extensively used to synthesize a variety of derivatives with applications ranging from catalysis [69] to materials science [70] and bioorganometallic chemistry [71]. Among the methods used to functionalize ferrocene compounds, deprotonative metallation plays an important role [72]. The presence of a substituent containing heteroatoms on ferrocene usually directs deprotonation to the adjacent position, giving after subsequent quenching 1,2-unsymmetrical ferrocenes. The reagents classically used for this purpose are lithium bases, which are highly polar reagents, hardly tolerating the presence of reactive functional groups. For these reason, restricted conditions 
such as low temperatures or solvents of low polarity have to be used in order to ensure good results, when attained.

In recent studies, ferrocene was mono- or poly-metallated using mixed alkali metalmagnesium, -zinc, and -manganese bases, and species were isolated and studied by X-ray diffraction [7]. Another mixed lithium-magnesium base, TMPMgCl-LiCl $(\mathrm{TMP}=2,2,6,6-$ tetramethylpiperidino), allowed chemoselective deprotonation reactions of ferrocenes bearing an ester, a nitrile and a carboxylic acid function, when used in a polar solvent at temperatures around $0^{\circ} \mathrm{C}[73]$.

It is known from the literature that ferrocene can be lithiated using 2 equivalents of tert-butyllithium in the presence of 0.1 equivalent of potassium tert-butoxide in $\mathrm{THF}$ at $-75^{\circ} \mathrm{C}$ [74]. When treated with 0.5 or 1 equiv of (TMP) $)_{3} \mathrm{CdLi}$ in THF at room temperature for $2 \mathrm{~h}$, ferrocene (44a) remained unchanged, as demonstrated by subsequent interception with iodine. In contrast, when the deprotonation step was carried out using 1 equiv of base at the reflux temperature of pentane for $3 \mathrm{~h}$, the iodide $\mathbf{4 4 b}$ was isolated in $86 \%$ yield (entry 1 ). Starting from tert-butylferrocene [75], a mixture of iodides was obtained under the same reaction conditions.

In the presence of a chelating group, the reaction was favoured. Thus, the similar functionalization of the acetal $\mathbf{4 5 a}$ could be performed either at the reflux temperature of pentane to afford the acetal-protected iodide $\mathbf{4 5 b}$ in $76 \%$ yield, or at room temperature in THF to give, after subsequent deprotection of the aldehyde, the derivative $\mathbf{4 5 b}$ ' in $51 \%$ overall yield. Using THF as solvent, the 2,5-diodo derivative 45c formed concomitantly, and was isolated in $10 \%$ yield (entries 2,3). Lithium bases were previously used to deprotonate the acetal 45a, but at lower temperatures in order to prevent substantial cleavage of the dioxane ring [76]. 
In order to estimate the chemoselectivity of reactions using $(\mathrm{TMP})_{3} \mathrm{CdLi}$, the metallation of ferrocene ketones was attempted. Starting from acetylferrocene and using THF or pentane as solvent logically resulted in a complex mixture presumably due to the presence of acidic $\alpha$-protons. From benzoylferrocene (46a), it proved possible, using 0.5 equivalent of base in THF at room temperature for $2 \mathrm{~h}$, to isolate the mono- and diiodide $46 \mathbf{b}, \mathbf{c}$ in 36 and $2 \%$ yield, respectively (entry 4 ).

Methyl ferrocenecarboxylate (47a) is less sensitive than the ketone $\mathbf{4 6 a}$, and thus gave best results. Indeed, employing only 0.5 equivalent of base resulted in the formation of the mono- and diiodide $\mathbf{4 7 b}, \mathbf{c}$ in 73 and $10 \%$ yield, respectively. The dimetallation was favoured using 1 equivalent of base, to furnish the diiodide $47 \mathrm{c}$ in $82 \%$ yield (entries 5,6).

Table 10. Metallation of ferrocenes 44a-47a using (TMP) ${ }_{3} \mathrm{CdLi}$ followed by trapping with $\mathrm{I}_{2}$.

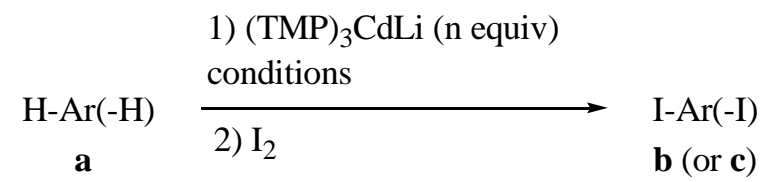

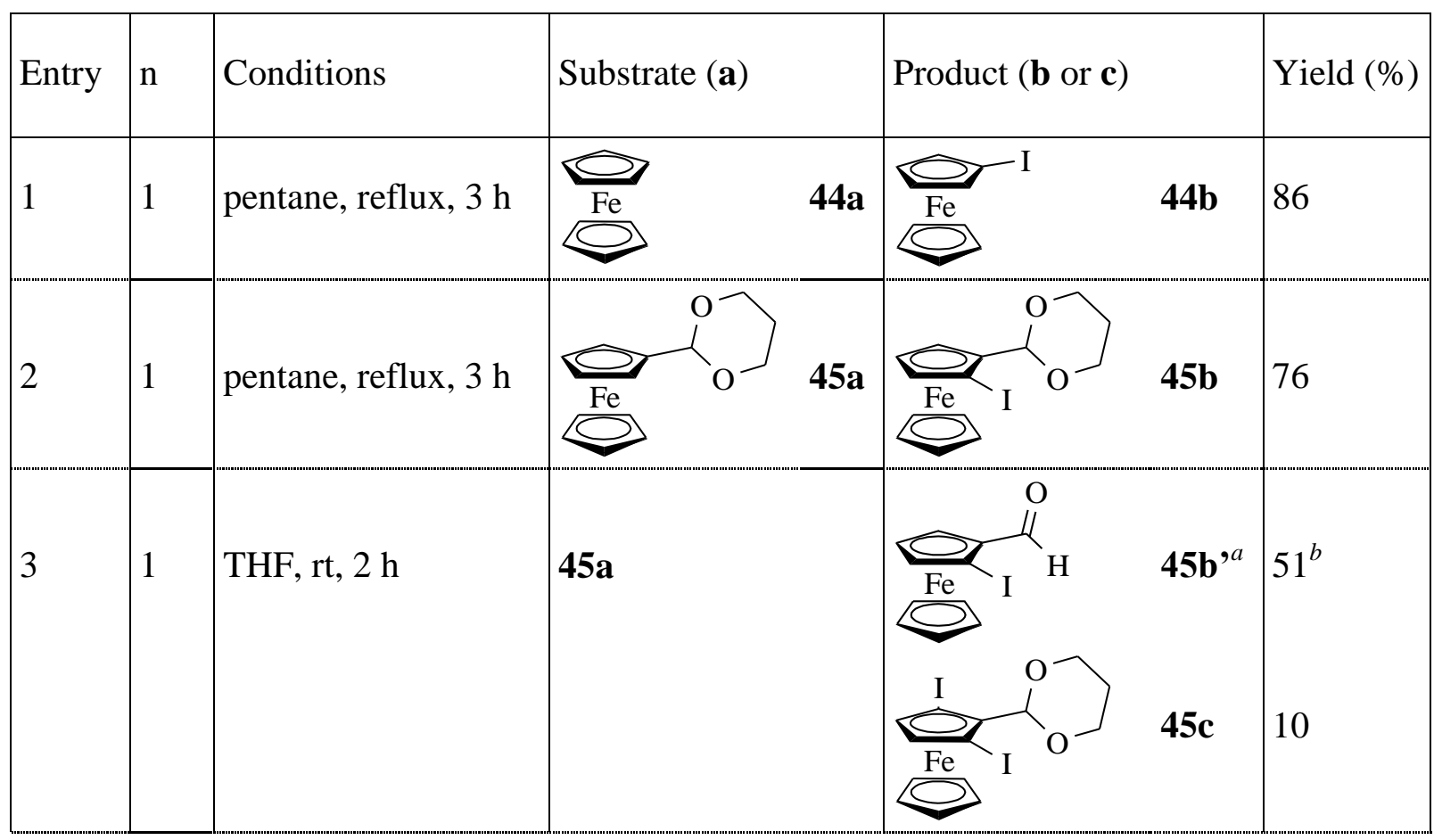




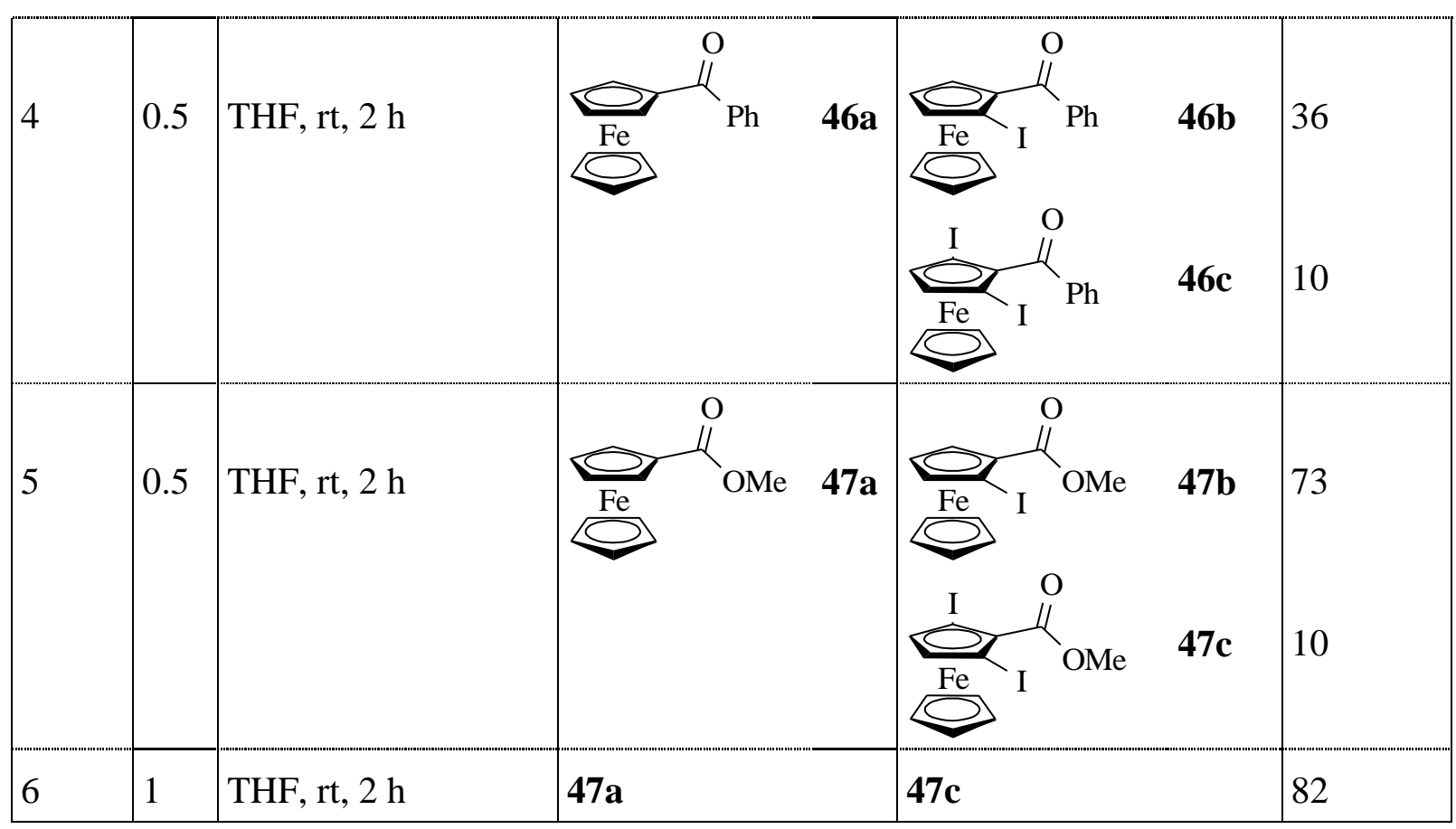

${ }^{a}$ After deprotection using PTSA, THF: $\mathrm{H}_{2} \mathrm{O} 1: 1,100^{\circ} \mathrm{C}, 1$ h. ${ }^{b}$ For two steps.

\section{TRAPPING OF LITHIUM ARYLCADMIATES}

If the reactivities of arylcadmium halides have been studied, few details concern the aromatic cadmiates [77].

\section{1) Direct trapping [20]}

Electrophiles known to react with alkali and alkali earth organometallic compounds were employed to trap the cadmiate generated from anisole (1a) and benzonitrile (5a) (Table 11). From anisole, reactions with 4-(trifluoromethyl)benzaldehyde, trimethylsilyl chloride, phenyl disulfide and allyl bromide at the reflux temperature of THF afforded the expected functionalized derivatives 1d-g, but in moderate yields ranging from 22 to $35 \%$ (entries 1-4). Worse, the cadmiate formed from benzonitrile (5a) did not react with 4(trifluoromethyl)benzaldehyde, trimethylsilyl chloride and phenyl disulfide under the same reaction conditions, and the allyl derivative $\mathbf{5 g}$ was isolated in a low $30 \%$ yield (entries 5-8). 
Table 11. Metallation of functionalized benzenes 1a and 5a using (TMP) ${ }_{3} \mathrm{CdLi}$ followed by direct trapping with electrophiles.

$$
\begin{aligned}
& \text { 1) (TMP })_{3} \mathrm{CdLi} \text { ( } 0.5 \text { equiv) } \\
& \begin{array}{clc}
\mathrm{Ar}-\mathrm{H} & \stackrel{\mathrm{THF}, \mathrm{RT}, 2 \mathrm{~h}}{\mathrm{a}} \underset{\mathrm{a}}{\mathrm{2} \text { Electrophile (1.5 equiv) }} & \begin{array}{c}
\text { Ar-E } \\
\text { d-g }
\end{array}
\end{array}
\end{aligned}
$$

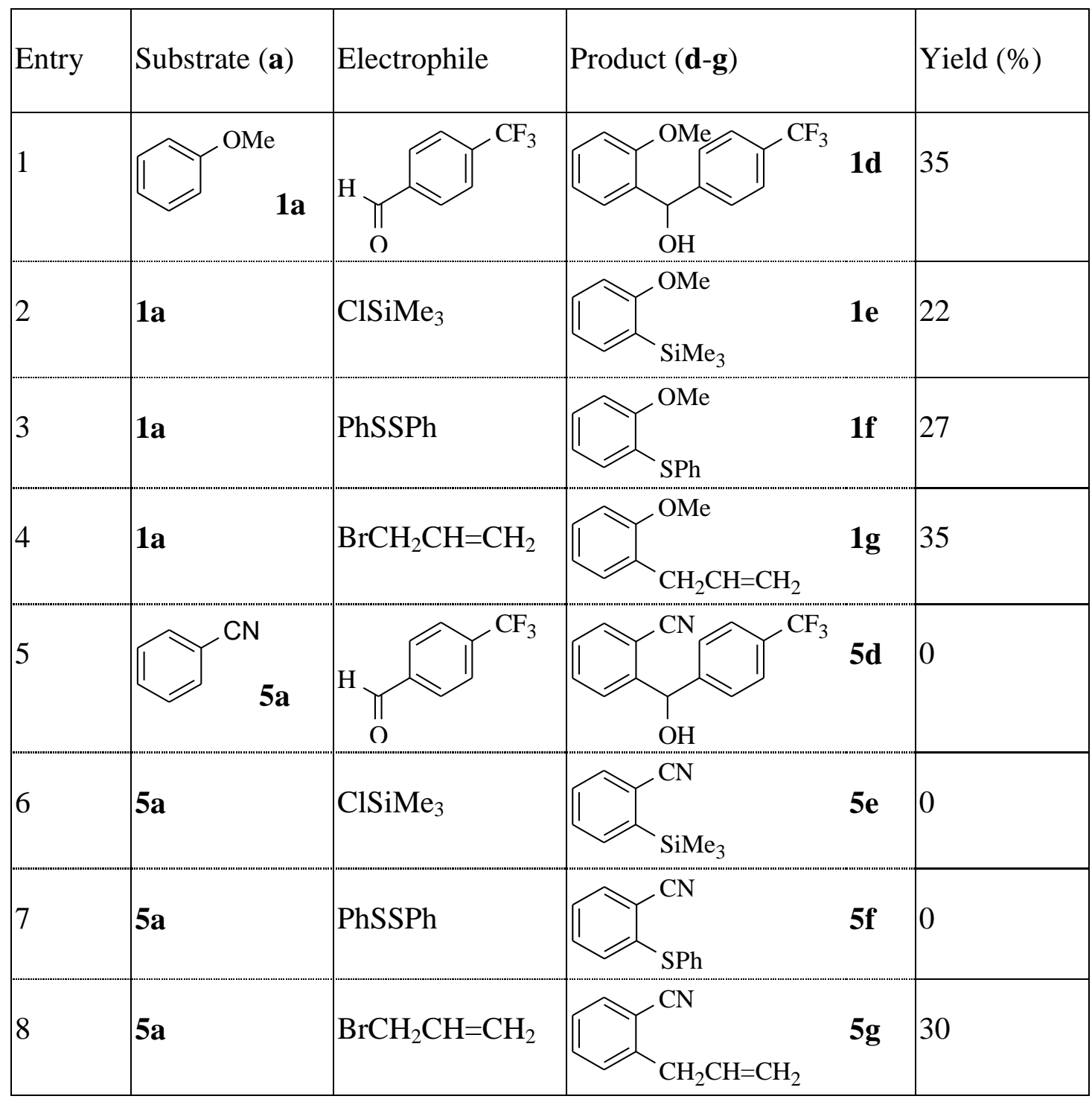

It is admitted that organocadmium halides can be trapped by acid chlorides to provide ketones [77]. This possibility was attempted from the cadmiate issued from furan (48a) using both aliphatic and aromatic acid chlorides (Table 12). The results clearly showed that nonenolizable electrophiles were more suitable for the reactions (entries 1-3). Methyl 
chloroformate allowed a direct access to the furan ester $\mathbf{4 8 h 4}$, albeit in a low yield that could be due to the volatility of the product (entry 4).

Gilman and Nelson reported in 1936 the reaction of diphenylcadmium with benzenesulfonyl chloride to give a mixture of diphenylsulfone, benzenesulfinic acid and chlorobenzene [78]. The furylcadmiate was involved in similar reactions with tosyl chloride and 4-chlorobenzenesulfonyl chloride to afford the expected diarylsulfones $\mathbf{4 8 h 5}$ and $\mathbf{4 8 h 6}$ in moderate yields (17-18\%, entries 5 and 6). Concomitant formation of 2-chlorofuran and 2,5dichlorofuran was suspected, even if not isolated due to their volatility [79]. Indeed, 5(arylsulfonyl)-2-chlorofurans $\mathbf{4 8}^{\prime} \mathbf{h 5}$ and $\mathbf{4 8}^{\prime} \mathbf{h} \mathbf{6}$ were also accessed in 5-6\% yield, probably through electrophilic trapping of the 2,5-dimetallated species through the two different modes. The disulfone was not detected, suggesting that benzenesulfonyl chlorides more likely act as chlorinated agents. Different diarylketones were finally obtained in medium to good yields when different benzoyl chlorides were chosen to intercept the furylcadmiate (entries 7-11).

Table 12. Metallation of furan (48a) using (TMP) ${ }_{3} \mathrm{CdLi}$ followed by direct trapping with acid chlorides.

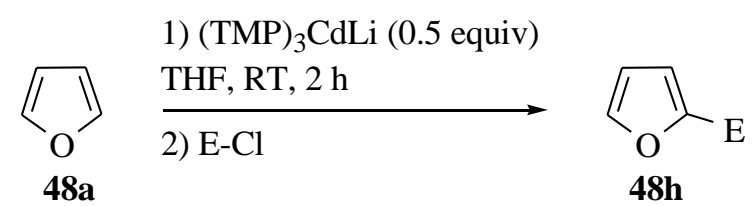

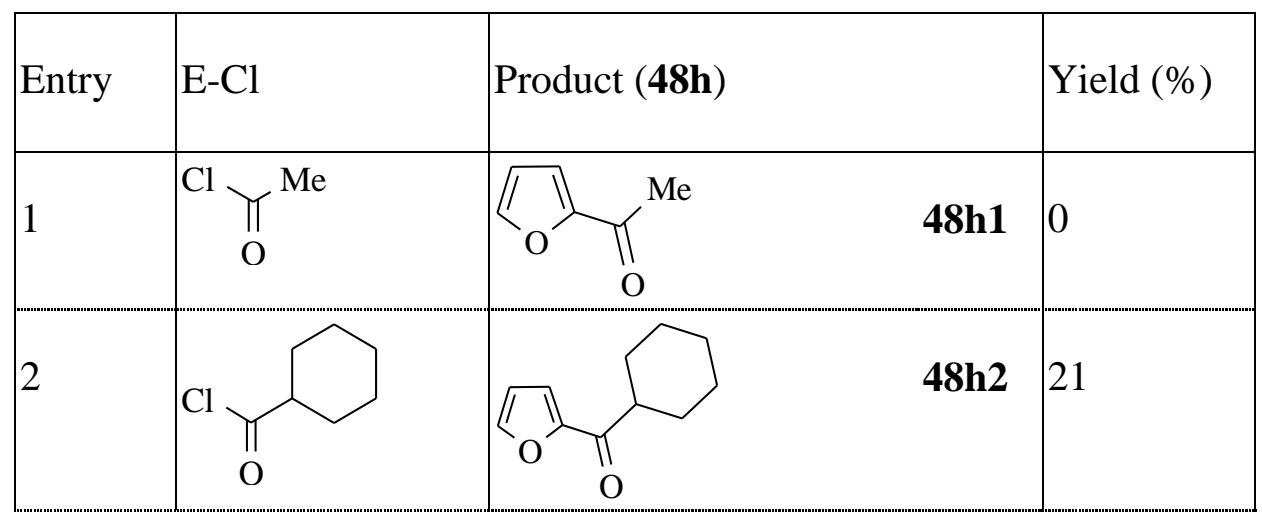




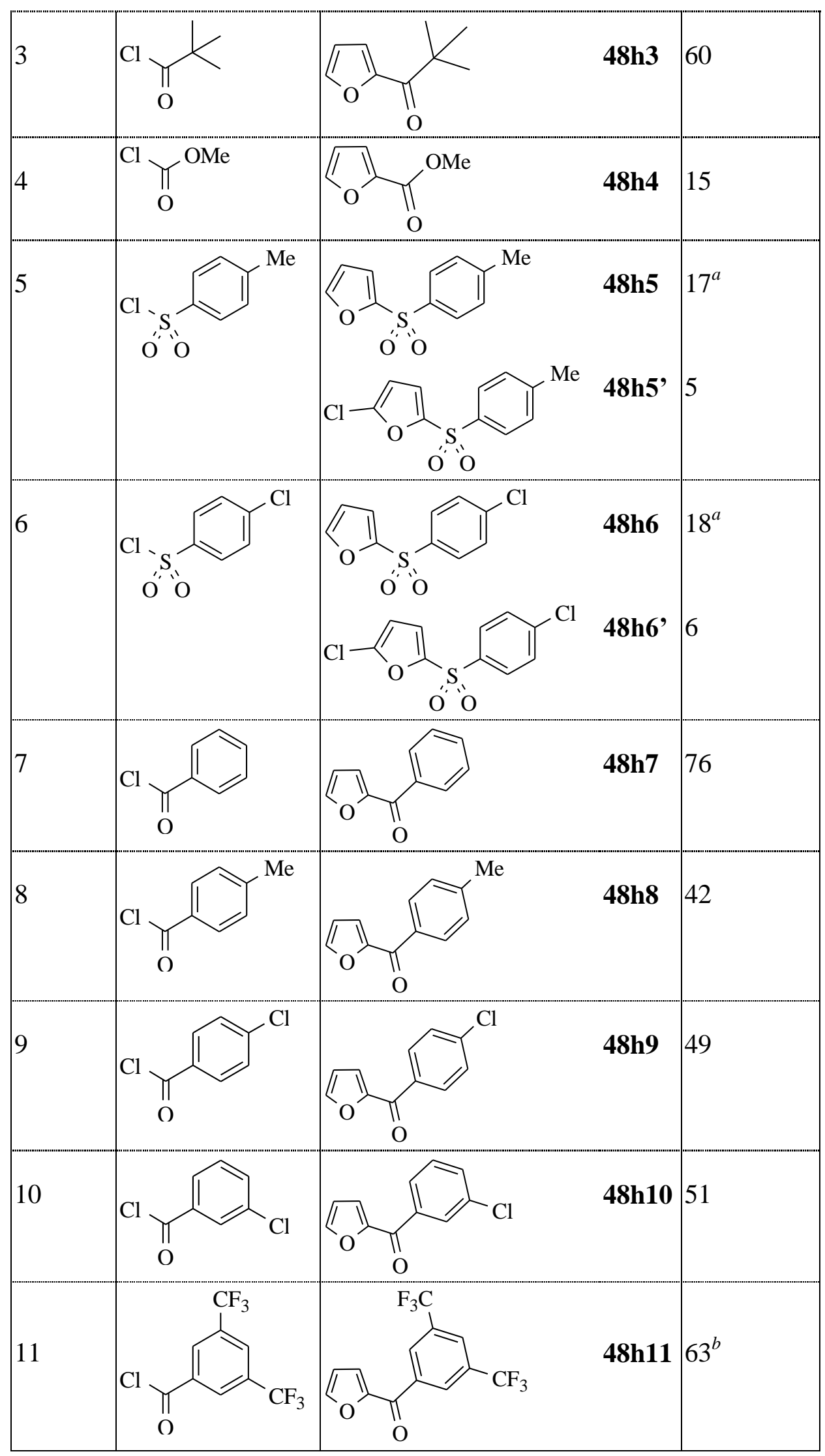

${ }^{a}$ 2-Chlorofuran and 2,5-dichlorofuran could be formed and evaporated under reduced pressure (b.p. $77^{\circ} \mathrm{C}$ [79a] and $115^{\circ} \mathrm{C}$ [79b], respectively). ${ }^{b}$ Bis[3,5-bis(trifluoromethyl)phenyl] furan-2,5-diyl diketone (48'h11) also formed, and was isolated in $3 \%$ yield. 


\section{2) Palladium-catalyzed trapping [20,26b,49]}

Before this study, cross-coupling reactions using cadmium compounds had only been described starting from organocadmium chlorides, and were known to produce, in addition to the expected products, homocoupling products derived from both substrates [80].

Heteroarylcadmiates have been involved in palladium-catalyzed cross-coupling reactions with aromatic bromides. The first reactions (Table 13) carried out at THF reflux using the 2-metallated thiophene or methyl benzoate, 2-bromopyridine, and a catalytic amount of palladium(0) tetrakis(triphenylphosphine) produced the expected products $\mathbf{1 8 i}$ and $\mathbf{4 i}$ in moderate to good yields (entries 1,2).

The results of reactions performed with palladium(0) tetrakis(triphenylphosphine) [81] being dependent on the quality of the later, a procedure using in situ generated palladium(0) was searched out. Reactions were then attempted in order to reproduce the results obtained from the 2-metallated thiophene and 2-bromopyridine. Palladium(II) chloride (2 mol.\%) was the first precatalyst used to this purpose, and monodentate triphenylphosphine (4 mol.\%) (entry 3) and bidentate 1,1'-bis(diphenylphosphino)ferrocene (dppf, 2 mol.\%) (entry 4) were compared. The latter proved superior, triphenylphosphine only allowing the cross-coupling when used in a larger amount $(10 \mathrm{~mol} . \%)$ (entry 5$)$. The cross-coupling between the 2 metallated furan and 4-bromoanisole was next investigated. Since the reaction failed using palladium(II) chloride ( $2 \mathrm{~mol} . \%)$ in the presence of dppf ( 2 mol.\%) (entry 6), an inefficient reduction of palladium(II) chloride was suspected, and another precatalyst was used. Palladium(II) acetate, for which mixtures with tertiary phosphines are known to spontaneously generate palladium(0) complexes [82], was chosen. A low $10 \%$ yield was obtained by using a 1:1 $\mathrm{Pd}(\mathrm{OAc})_{2}: \operatorname{dppf}$ ratio (2 mol.\% each) (entry 7$)$, but increasing this ratio to 2:1 and 3:1 resulted in improved yields of 51 and 83\%, respectively (entries 8 and 9). 
Table 13. Metallation of substrates 4a, 18a and 48a using (TMP) $)_{3} \mathrm{CdLi}$ followed by crosscoupling (optimization).

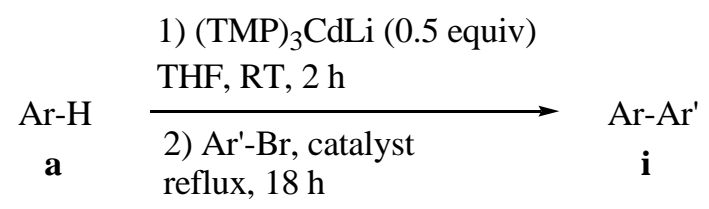

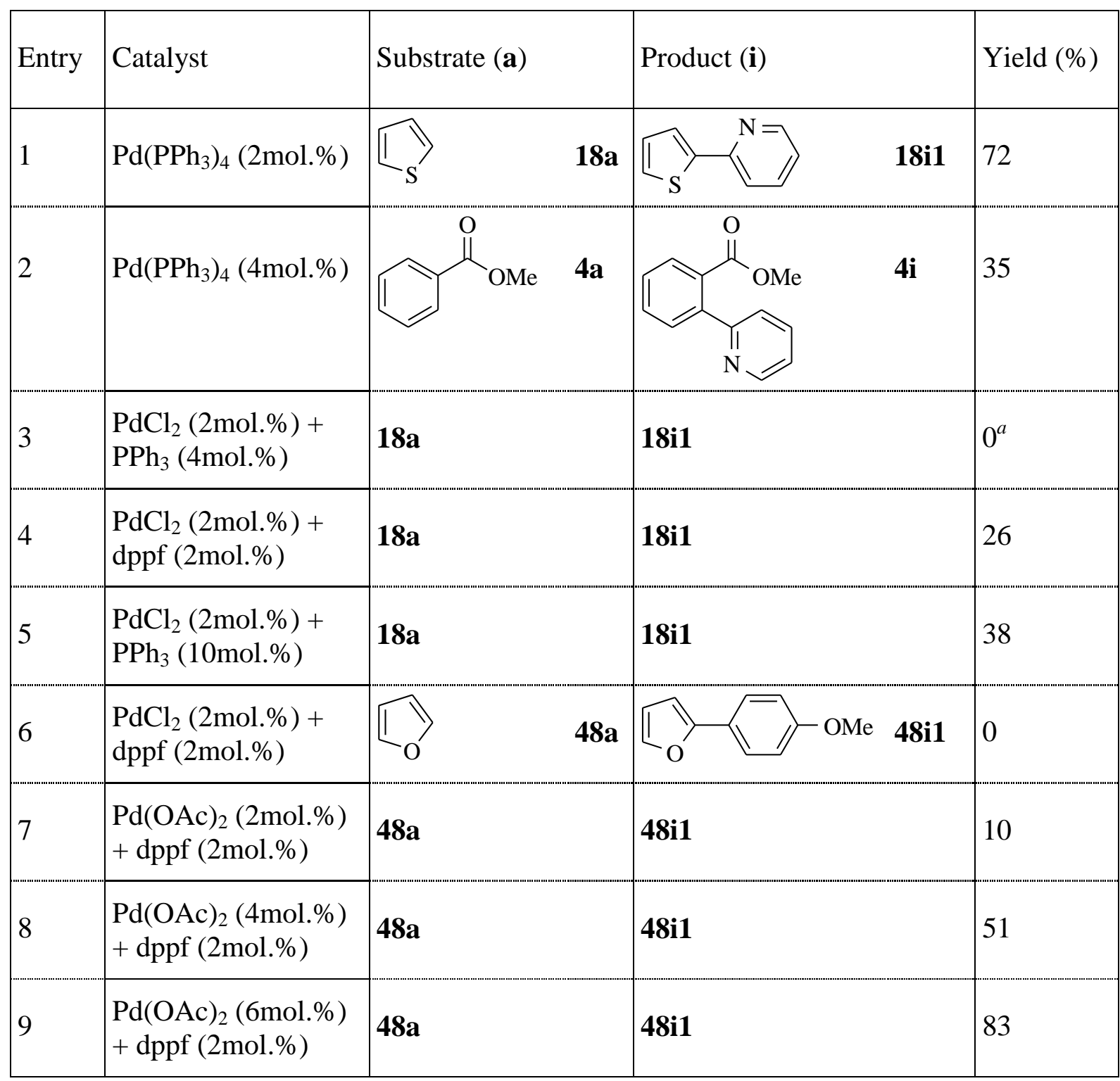

${ }^{a}$ No improvement was observed using $\mathrm{Pd}\left(\mathrm{PPh}_{3}\right)_{2} \mathrm{Cl}_{2}(2 \mathrm{~mol} . \%)$.

To evaluate the scope of this reaction, experiments employing other metallated aromatics and different aryl bromides were conducted under the optimized reaction conditions 
(Table 14). The expected biaryl compounds could be isolated, albeit in medium yields due to concomitant formation of homocoupling products. From pyrimidine (38a) and $[1,2,3]$ triazolo[1,5-a]pyridine (32a), lower yields were obtained, probably in relation with the lower stability of the metallated species (entries 11,12).

Table 14. Metallation using (TMP) ${ }_{3} \mathrm{CdLi}$ followed by cross-coupling (scope).

1) $(\mathrm{TMP})_{3} \mathrm{CdLi}(0.5$ equiv)

THF, RT, 2 h

\begin{tabular}{clc}
$\operatorname{Ar}-\mathrm{H}$ & $\mathrm{Ar}-\mathrm{Ar}^{\prime}$ \\
\cline { 2 - 3 } & $2) \mathrm{Ar}^{\prime}-\mathrm{Br}$ & $\mathbf{i}$ \\
& $\operatorname{Pd}(\mathrm{OAc})_{2}(6 \mathrm{~mol} . \%)$ & \\
& $\operatorname{dppf}(2 \mathrm{~mol} . \%)$ & \\
& $\operatorname{reflux}, 18 \mathrm{~h}$ &
\end{tabular}

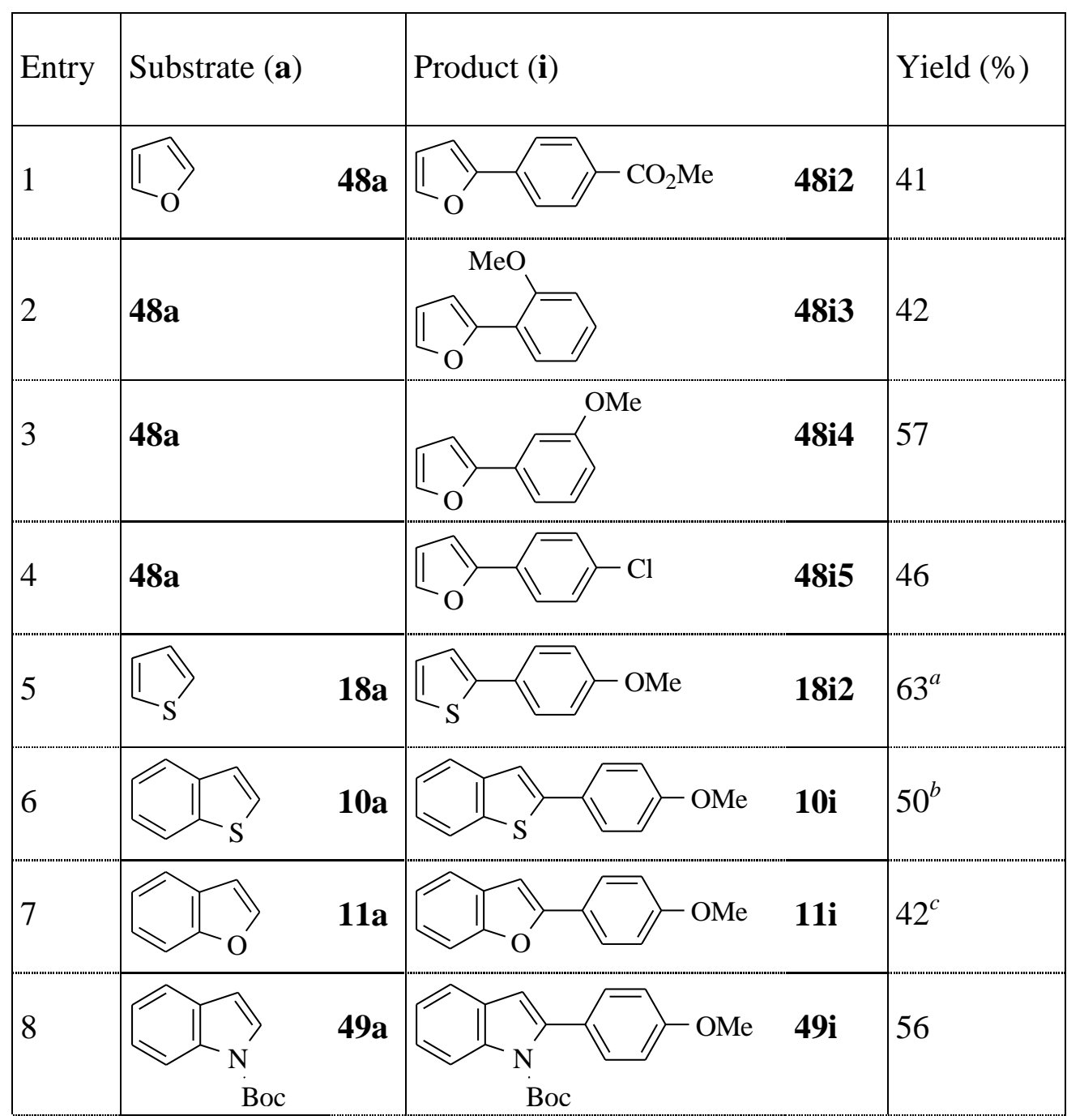




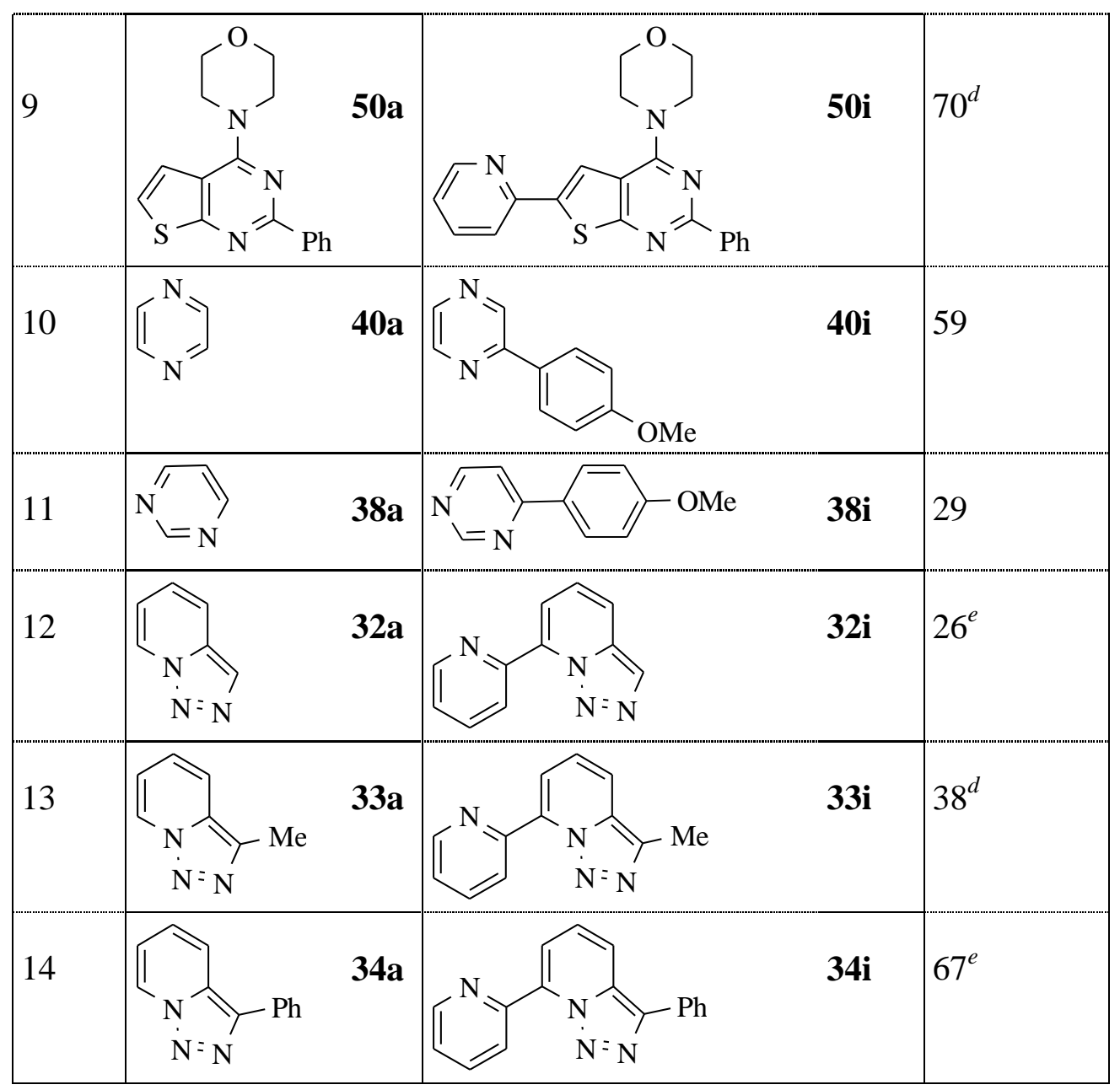

${ }^{a}$ 2,5-Bis(4-methoxyphenyl)thiophene was isolated in $16 \%$ yield. ${ }^{b} 2,2^{\prime}$ Bis(benzo $[b]$ thiophene) was isolated in $25 \%$ yield. ${ }^{c} 2,2^{\prime}$-Bis(benzo[b]furan) was isolated in $12 \%$ yield. ${ }^{d}$ Using 1 equiv of base. ${ }^{e}$ Using 0.4 equiv of base.

Compared to the previously described methods for the synthesis of similar biaryl compounds, the procedure described here has the advantage of being 'one pot'.

\section{COMPUTATIONAL STUDY [22]}

Density functional theory (DFT) calculations have been performed to understand the deprotonative metalation using cadmate bases. All calculations were carried with the Gaussian 03 program package [83]. The molecular structures and harmonic vibrational frequencies were obtained using the hybrid density functional method based on Becke's threeparameter exchange function and the Lee-Yang-Parr nonlocal correlation functional 
(B3LYP) [84]. We used Ahlrichs' SVP [85,86] all-electron basis set for the zinc and iodine atom and $6-31 G^{*}$ for the other atoms (denoted as 631SVPs in the text). Geometry optimization and vibrational analysis were performed at the same level. All stationary points were optimized without any symmetry assumptions, and characterized by normal coordinate analysis at the same level of theory (number of imaginary frequencies, NIMAG, 0 for minima and 1 for TSs). We employed $\left(\mathrm{Me}_{2} \mathrm{~N}\right)_{3} \mathrm{CdLi}, \mathrm{MeCd}\left(\mathrm{NMe}_{2}\right)_{2} \mathrm{Li}$ and $\mathrm{Me}_{2} \mathrm{Cd}\left(\mathrm{NMe}_{2}\right) \mathrm{Li}$ as models for $(\mathrm{TMP})_{3} \mathrm{CdLi}, \mathrm{RCd}(\mathrm{TMP})_{2} \mathrm{Li}$ and $\mathrm{R}_{2} \mathrm{Cd}(\mathrm{TMP}) \mathrm{Li}$, respectively. A molecule of $\mathrm{Me}_{2} \mathrm{O}$ (instead of THF) was incorporated to complete lithium atom coordination.

\section{1) Reaction Pathway of Deprotonation of Anisole with Lithium} tris(Dimethylamino)cadmate (Figure 1)

Among several possibilities for the deprotonation reaction using $\left(\mathrm{Me}_{2} \mathrm{~N}\right)_{3} \mathrm{CdLi}$, two plausible reaction pathways through Li-assisted and Cd-assisted deprotonation TSs (TS1 and TS2) were identified. In both cases, the reaction coordinates started with formation of a relatively stable initial complex (IM1 or IM2) between anisole oxygen and the counter cation $\mathrm{Li}$ or the central $\mathrm{Cd}$ metal. This indicated that the regioselectivity of the ortho cadmation reaction can be explained by a coordinative approximation effect between functional group and the $\mathrm{Li}$ or $\mathrm{Cd}$ metal, enabling initial complex formation and orienting the ate base ligand exclusively toward aromatic ortho hydrogen. According to path 1, the Li-assisted deprotonation is a similar pathway to that seen in TMP-Zn-ate mediated DoM reactions [8g], and takes place via "open form TS" (TS1) with a reasonable activation energy $(+22.0$ $\mathrm{kcal} / \mathrm{mol}$ ). The Cd-assisted deprotonation (path 2), a unique pathway of this Cd-ate base, proceeds smoothly with a smaller activation energy $(19.5 \mathrm{kcal} / \mathrm{mol})$. This deprotonation is facilitated by the direct push-pull synergy of the Lewis acidic Cd metal and the negatively charged $\mathrm{NMe}_{2}$ moiety to generate a stable product (PD2). The stabilization energy is very 
large $(-26.8 \mathrm{kcal} / \mathrm{mol})$, because this deprotonation occurs with maintenance of the stable $\mathrm{Me}_{2} \mathrm{~N}^{\cdots} \mathrm{Li}^{\cdots} \mathrm{NMe}_{2}$ coordination.

Figure 1. Reactants, intermediates, complexes, and TSs in the deprotonation reaction of anisole with $\left(\mathrm{Me}_{2} \mathrm{~N}\right)_{3} \mathrm{CdLi}$. Bond lengths and energy changes at the B3LYP/631SVPs level are shown in $\AA$ and kcal/mol, respectively.
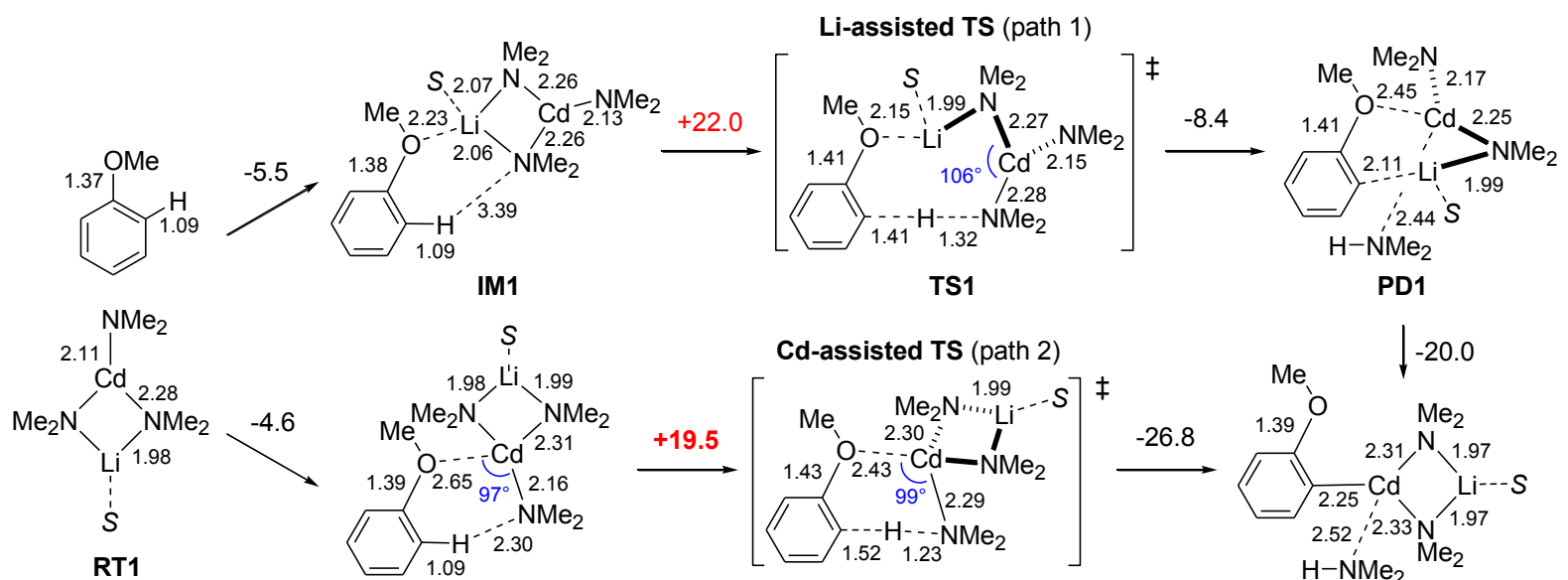

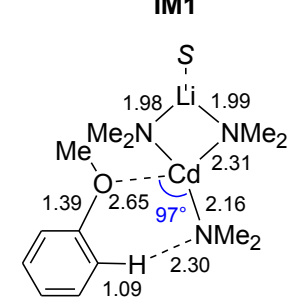

IM2

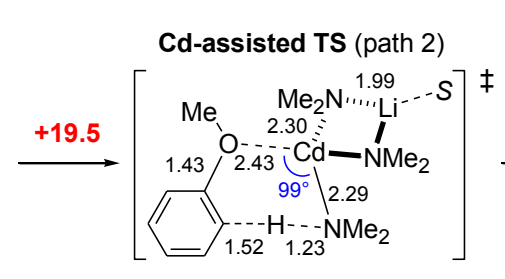

TS2

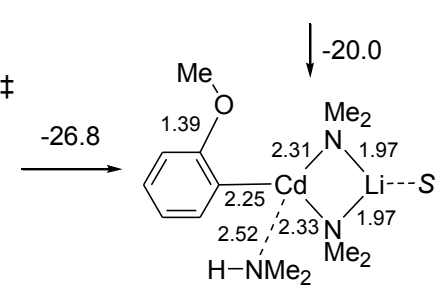

PD2

\section{2) Reaction Pathway of Deprotonation of Anisole with Lithium}

\section{bis(Dimethylamino)alkylcadmate (Figure 2)}

The computational results of deprotonation with $\mathrm{MeCd}\left(\mathrm{NMe}_{2}\right)_{2} \mathrm{Li}$ indicated that the Li-assisted pathway via the "open form" TS (path 3) is the most probable. In this pathway, the DoM reaction proceeds through $\mathbf{T S 3}$ by using one of the $\mathrm{Me}_{2} \mathrm{~N}$ ligands of $\mathrm{MeCd}\left(\mu-\mathrm{NMe}_{2}\right)_{2} \mathrm{Li}$ (in RT2). The activation energy of path 3 is $4.4 \mathrm{kcal} / \mathrm{mol}$ higher than that of the $\mathrm{Cd}$-assisted pathway (path 2) in the reaction with $\left(\mathrm{Me}_{2} \mathrm{~N}\right)_{3} \mathrm{CdLi}$. This calculation indicates that the reaction of $\mathrm{RCd}(\mathrm{TMP})_{2} \mathrm{Li}$ proceeds as well as the reaction of $(\mathrm{TMP})_{3} \mathrm{CdLi}$. The reaction pathway via the "closed form" TS4 (path 4) is rather unfavorable. A Cd-assisted deprotonation pathway (path 5) was also identified and the activation energy $(+20.2 \mathrm{kcal} / \mathrm{mol})$ is energetically more favorable than that of the Li-assisted "open form" pathway (path 3) by 
$3.7 \mathrm{kcal} / \mathrm{mol}$ because of direct activation of the $\mathrm{Cd}-\mathrm{N}$ bond by anisole oxygen. This pathway, however, first requires the reformation of the most stable symmetric cadmate in RT2 to an unstable unsymmetric one in RT3, including the dissociation of the stable $\mathrm{Li}^{\cdots} \mathrm{N}$ bond $-\mathrm{a}$ process leading the $16.2 \mathrm{kcal} / \mathrm{mol}$ loss of energy. Therefore, this pathway is much less likely to take place than those of Li-assisted deprotonation shown in Figure 2.

Figure 2. Reactants, Intermediates, Complexes, and TSs in the Deprotonation Reaction of Anisole with $\mathrm{MeCd}\left(\mathrm{NMe}_{2}\right)_{2} \mathrm{Li}$. Bond lengths and energy changes at the B3LYP/631SVPs level are shown in $\AA$ and kcal/mol, respectively.

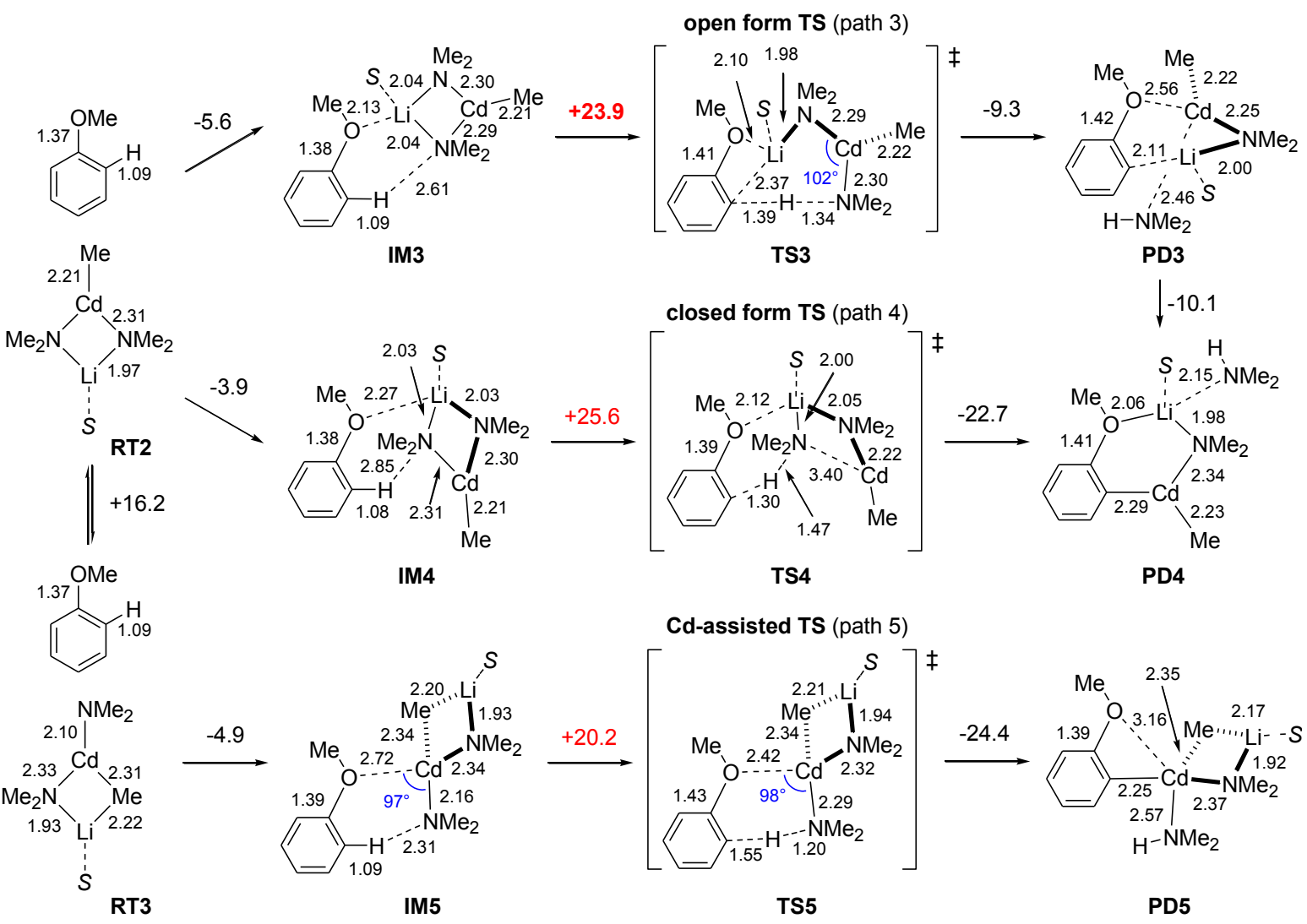

3) Reaction Pathway of Deprotonation of Anisole with Lithium

\section{Dialkyl(dimethylamino)cadmate (Figure 3)}

Two structures are also a priori possible for $\mathrm{Me}_{2} \mathrm{Cd}\left(\mathrm{NMe}_{2}\right) \mathrm{Li}$, i.e. the unsymmetrical one (in RT4) and the symmetrical one (in RT5): the former structure is computed to be much 
more stable, mainly due to the stable $\mathrm{Me}_{2} \mathrm{~N}^{\cdots} \mathrm{Li}$, than the latter one by $17.0 \mathrm{kcal} / \mathrm{mol}$. Initial electrostatic coordination of $\mathrm{Li}$ to anisole oxygen occurs, resulting in the formation of a complex (IM6) with a stabilization energy of $7.4 \mathrm{kcal} / \mathrm{mol}$. From IM6, the DoM reaction using the $\mathrm{Me}_{2} \mathrm{~N}$ ligand can take two pathways through TS6 ("closed form" TS, path 6) and TS7 ("open form" TS, path 7). Although the activation energies are only $0.7 \mathrm{kcal} / \mathrm{mol}$ higher than that of the DoM reaction with $\mathrm{MeCd}\left(\mu-\mathrm{NMe}_{2}\right)_{2} \mathrm{Li}$ (path 3), the deprotonation occurs with more than $10 \mathrm{kcal} / \mathrm{mol}$ endothermicity. This large energy loss is a result of the cleavage of the stable $\mathrm{Me}_{2} \mathrm{~N}^{\cdots} \mathrm{Li}$ bond and of the rather small energy gain to form a $\mathrm{C}^{\cdots} \mathrm{Li}$ bond at the expense of the $\mathrm{Me}_{2} \mathrm{~N}^{\cdots} \mathrm{Li}$ bond cleavage. These results indicate that path 6 and 7 are kinetically favored but thermodynamically unfavored. The computed predilection accounts for the experimental observation that dialkylamidocadmate complexes are almost inert in the deprotonative cadmation reaction of anisole. Deprotonation by the $\mu$-Me ligand on Cd (path 8) was also found to be kinetically unfavorable, requiring a much higher activation energy of $32.7 \mathrm{kcal} / \mathrm{mol}$.

Figure 3. Reactants, Intermediates, Complexes, and TSs in the Deprotonation Reaction of Anisole with $\mathrm{Me}_{2} \mathrm{Cd}\left(\mathrm{NMe}_{2}\right) \mathrm{Li}$. Bond lengths and energy changes at the B3LYP/631SVPs level are shown in $\AA$ and $\mathrm{kcal} / \mathrm{mol}$, respectively. 


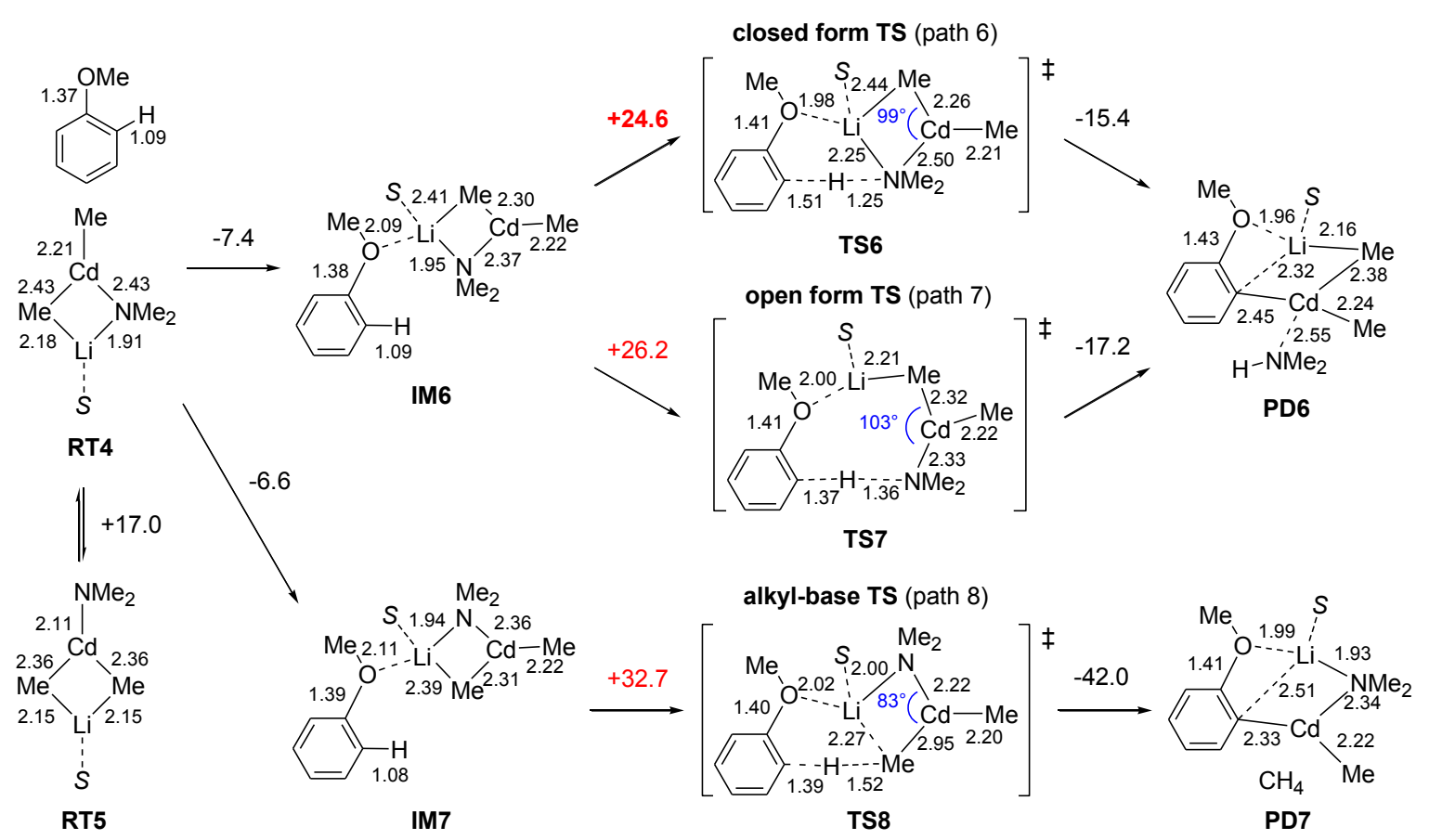

From the mechanistic point of view, the DFT calculations revealed that the metalation with (TMP) ${ }_{3} \mathrm{CdLi}$ proceeds through a Cd-assisted transition state while pathways with higher activation energies and Li-assisted transition states were found with $\mathrm{RCd}(\mathrm{TMP})_{2} \mathrm{Li}$ and $\mathrm{R}_{2} \mathrm{Cd}(\mathrm{TMP}) \mathrm{Li}(\mathrm{R}=$ alkyl). The mechanism of the anisole deprotonation using TMP-dialkyl zincates has been the subject of studies [8g,i]. A two-step mecanism has been proposed where the lithium zincate first acts as an amino base, and thus generated HTMP then returns back to zinc through 2-anisyl- or R-mediated deprotonation. Studies will be soon started in order to identify the species present in reaction mixtures coming from metalation steps using Li-Cd combinations, and to possibly propose more complete mechanisms.

\section{CONCLUSION}

In summary, efficient deprotonative cadmiation reactions of functionalized aromatics including heterocycles were realized using the newly developed TMP-cadmiate base. The latter proved compatible with reactive functional groups $\left(\mathrm{CONEt}_{2}, \mathrm{CO}_{2} \mathrm{Me}, \mathrm{CN}, \mathrm{COPh}\right)$, 
heavy halogens $(\mathrm{Br}, \mathrm{I})$, and sensitive aromatic aza-heterocycles. Heterocycles benefiting from doubly activated positions were similarly dideprotonated at room temperature.

The aromatic lithium cadmiates were evidenced using iodine; the species were then involved in palladium-catalyzed cross-coupling reactions or simply quenched with acid chlorides in order to extent the synthetic applications of the method.

Due to the toxicity of cadmium compounds [87], new mixed lithium-metal bases of ate type, still efficient and chemoselective, are under development, profiting from the present study.

\section{ACKNOWLEDGEMENTS}

We thank all the co-workers for their contribution to the development of this fascinating chemistry.

\section{REFERENCES AND NOTES}

[1] For excellent reviews, see: (a) Gschwend, H. W.; Rodriguez, H. R. Org. React., 1979, 26, 1-360; (b) Beak, P.; Snieckus, V. Acc. Chem. Res., 1982, 15, 306-312; (c) Snieckus, V. Chem. Rev., 1990, 90, 879-933; (d) Gant, T. G.; Meyers, A. I. Tetrahedron, 1994, 50, 2297-2360; (e) Schlosser, M. in Organometallics in Synthesis, $2^{\text {nd }}$ ed. (Ed.: M. Schlosser), Wiley, 2002, Chapter I.

[2] See for example: (a) Eaton, P. E.; Lee, C. H.; Xiong, Y. J. Am. Chem. Soc., 1989, 111, 8016-8018; (b) Schlecker, W.; Huth, A.; Ottow, E.; Mulzer, J. J. Org. Chem., 1995, $60,8414-8416$.

[3] Schlosser, M. Pure Appl. Chem., 1988, 60, 1627-1634.

[4] Lochmann, L. Eur. J. Inorg. Chem., 2000, 7, 1115-1126.

[5] Caubère, P. Chem. Rev., 1993, 93, 2317-2334. 
[6] (a) Gros, P.; Fort, Y. Eur. J. Org. Chem., 2002, 3375-3383. (b) Gros, P.; Fort, Y. Eur. J. Org. Chem., 2009, 4199-4209.

[7] For reviews, see: (a) Mulvey, R. E. Organometallics, 2006, 25, 1060-1075; (b) Mulvey, R. E.; Mongin, F.; Uchiyama, M.; Kondo, Y. Angew. Chem. Int. Ed., 2007, 46, 3802-3824 (Angew. Chem., 2007, 119, 3876-3899); (c) Mulvey, R. E. Acc. Chem. Res., 2009, 42, 743-755.

[8] (a) Kondo, Y.; Shilai, M.; Uchiyama, M.; Sakamoto, T. J. Am. Chem. Soc., 1999, 121, 3539-3540. (b) Uchiyama, M.; Miyoshi, T.; Kajihara, Y.; Sakamoto, T.; Otani, Y.; Ohwada, T. Kondo, Y. J. Am. Chem. Soc., 2002, 124, 8514-8515. (c) Barley, H. R. L.; Clegg, W.; Dale, S. H.; Hevia, E.; Honeyman, G. W.; Kennedy, A. R.; Mulvey, R. E. Angew. Chem. Int. Ed., 2005, 44, 6018-6021 (Angew. Chem., 2005, 117, 6172-6175). (d) Clegg, W.; Dale, S. H.; Hevia, E.; Honeyman, G. W.; Mulvey, R. E. Angew. Chem. Int. Ed., 2006, 45, 2370-2374 (Angew. Chem., 2006, 118, 2430-2434). (e) Clegg, W.; Dale, S. H.; Harrington, R. W.; Hevia, E.; Honeyman, G. W.; Mulvey, R. E. Angew. Chem. Int. Ed., 2006, 45, 2374-2377 (Angew. Chem., 2006, 118, 2434-2437). (f) Clegg, W.; Dale, S. H.; Drummond, A. M.; Hevia, E.; Honeyman, G. W.; Mulvey, R. E. J. Am. Chem. Soc., 2006, 128, 7434-7435. (g) Uchiyama, M.; Matsumoto, Y.; Nobuto, D.; Furuyama, T.; Yamaguchi, K.; Morokuma, K. J. Am. Chem. Soc., 2006, 128, 8748-8750. (h) Uchiyama, M.; Kobayashi, Y.; Furuyama, T.; Nakamura, S.; Kajihara, Y.; Miyoshi, T.; Sakamoto, T.; Kondo, Y.; Morokuma, K. J. Am. Chem. Soc., 2008, 130, 472-480. (i) Clegg, W.; Conway, B.; Hevia, E.; McCall, M. D.; Russo, L.; Mulvey, R. E. J. Am. Chem. Soc., 2009, 131, 2375-2384.

[9] (a) Wunderlich, S. H.; Knochel, P. Angew. Chem. Int. Ed., 2007, 46, 7685-7688 (Angew. Chem., 2007, 119, 7829-7832). (b) Wunderlich, S.; Knochel, P. Chem. 
Commun., 2008, 6387-6389. (c) Wunderlich, S. H.; Knochel, P. Org. Lett., 2008, 10, 4705-4707. (d) Mosrin, M.; Knochel, P. Chem. Eur. J., 2009, 15, 1468-1477.

[10] Mosrin, M.; Knochel, P. Org. Lett., 2009, 11, 1837-1840.

[11] (a) Uchiyama, M.; Naka, H.; Matsumoto, Y.; Ohwada, T. J. Am. Chem. Soc., 2004, 126, 10526-10527. (b) Garcia-Alvarez, J.; Graham, D. V.; Kennedy, A. R.; Mulvey, R. E.; Weatherstone, S. Chem. Commun., 2006, 30, 3208-3210. (c) Garcia-Alvarez, J.; Hevia, E.; Kennedy, A. R.; Klett, J.; Mulvey, R. E. Chem. Commun., 2007, 24022404. (d) Conway, B.; Hevia, E.; García-Álvarez, J.; Graham, D. V.; Kennedy, A. R.; Mulvey, R. E. Chem. Commun., 2007, 5241-5243. (e) Naka, H.; Uchiyama, M.; Matsumoto, Y.; Wheatley, A. E. H.; McPartlin, M.; Morey, J. V.; Kondo, Y. J. Am. Chem. Soc., 2007, 129, 1921-1930. (f) Naka, H.; Morey, J. V.; Haywood, J.; Eisler, D. J.; McPartlin, M.; Garcia, F.; Kudo, H.; Kondo, Y.; Uchiyama, M.; Wheatley, A. E. H. J. Am. Chem. Soc., 2008, 130, 16193-16200.

[12] Wunderlich, S. H.; Knochel, P. Angew. Chem. Int. Ed., 2009, 48, 1501-1504 (Angew. Chem., 2009, 121, 1530-1533).

[13] Garcia-Álvarez, J.; Kennedy, A. R.; Klett, J.; Mulvey, R. E. Angew. Chem. Int. Ed., 2007, 46, 1105-1108 (Angew. Chem., 2007, 119, 1123-1126).

[14] Usui, S.; Hashimoto, Y.; Morey, J. V.; Wheatley, A. E. H.; Uchiyama, M. J. Am. Chem. Soc., 2007, 129, 15102-15103.

[15] Handley, D. A.; Hitchcock, P. B.; Lee, T. H.; Leigh, G. J. Inorg. Chem. Acta, 2001, $316,59-64$.

[16] Isobe, M.; Kondo, S.; Nagasawa, N.; Goto, T. Chem. Lett., 1977, 679-682.

[17] Kedarnath, G.; Kumbhare, L. B.; Jain, V. K.; Phadnis, P. P.; Nethaji, M. Dalton Trans., 2006, 2714-2718. 
[18] Nguyen, T. T.; Chevallier, F.; Jouikov, V.; Mongin, F. Tetrahedron Lett., 2009, 50, 6787-6790.

[19] (a) L'Helgoual'ch, J.-M.; Seggio, A.; Chevallier, F.; Yonehara, M.; Jeanneau, E.; Uchiyama, M.; Mongin, F. J. Org. Chem., 2008, 73, 177-183. See also: (b) Seggio, A.; Lannou, M.-I.; Chevallier, F.; Nobuto, D.; Uchiyama, M.; Golhen, S.; Roisnel, T.; Mongin, F. Chem. Eur. J., 2007, 13, 9982-9989; (c) Seggio, A.; Chevallier, F.; Vaultier, M.; Mongin, F. J. Org. Chem., 2007, 72, 6602-6605.

[20] (a) L'Helgoual'ch, J.-M.; Bentabed-Ababsa, G.; Chevallier, F.; Yonehara, M.; Uchiyama, M.; Derdour, A.; Mongin, F. Chem. Commun., 2008, 5375-5377. (b) Snégaroff, K.; L'Helgoual'ch, J.-M.; Bentabed-Ababsa, G.; Nguyen, T. T.; Chevallier, F.; Yonehara, M.; Uchiyama, M.; Derdour, A.; Mongin, F. Chem. Eur. J., 2009, 15, 10280-10290.

[21] Wittig, G.; Meyer, F. J.; Lange, G. Liebigs Ann. Chem., 1951, 571, 167-201.

[22] Snégaroff, K.; Komagawa, S.; Yonehara, M.; Chevallier, F.; Gros, P. C.; Uchiyama, M.; Mongin, F. J. Org. Chem., in press.

[23] For the catalytic effect of $\mathrm{LiCl}$ on ortholithiations, see: Gupta, L.; Hoepker, A. C.; Singh, K. J.; Collum, D. B. J. Org. Chem., 2009, 74, 2231-2233, and references cited therein.

[24] Even if its effect in accelerating the rates of deprotonation remains small: Fraser, R. R.; Mansour, T. S. Tetrahedron Lett., 1986, 27, 331-334.

[25] For previously described metallation of 4-iodoanisole at room temperature, see Ref. [11a,e].

[26] (a) Bentabed-Ababsa, G.; Cheikh Sid Ely, S.; Hesse, S.; Nassar, E.; Chevallier, F.; Nguyen, T. T.; Derdour, A.; Mongin, F. J. Org. Chem., in press. (b) Snégaroff, K.; 
Lassagne, F.; Bentabed-Ababsa, G.; Nassar, E.; Cheikh Sid Ely, S.; Hesse, S.; Perspicace, E.; Derdour, A.; Mongin, F. Org. Biomol. Chem., 2009, 7, 4782-4788.

[27] (a) Katritzky, A. R. in Handbook of Heterocyclic Chemistry, $1^{\text {st }}$ ed.; Pergamon: New York, NY, 1985. (b) Eicher, T.; Hauptmann, S.; Speicher, A. in The Chemistry of Heterocycles, $2^{\text {nd }}$ ed., Wiley-VCH, 2003.

[28] (a) Metzger, J.; Koether, B. Bull. Chem. Soc. Fr., 1953, 702-707. (b) Marxer, A.; Siegrist, M. Helv. Chim. Acta, 1974, 57, 1988-2000. (c) Boga, C.; Del Vecchio, E.; Forlani, L.; Milanesi, L.; Todesco, P. E. J. Organomet. Chem., 1999, 588, 155-159. (d) Rao, P. D.; Littler, B. J.; Geier III, G. R.; Lindsey, J. S. J. Org. Chem., 2000, 65, 1084-1092.

[29] (a) Bayh, O.; Awad, H.; Mongin, F.; Hoarau, C.; Bischoff, L.; Trécourt, F.; Quéguiner, G.; Marsais, F.; Blanco, F.; Abarca, B.; Ballesteros, R. J. Org. Chem., 2005, 70, 5190-5196. (b) Bayh, O.; Awad, H.; Mongin, F.; Hoarau, C.; Trecourt, F.; Queguiner, G.; Marsais, F.; Blanco, F.; Abarca, B.; Ballesteros, R. Tetrahedron, 2005, 61, 4779-4784. (c) Mongin, F.; Bucher, A.; Bazureau, J. P.; Bayh, O.; Awad, H.; Trécourt, F. Tetrahedron Lett., 2005, 46, 7989-7992. (d) Rohbogner, C. J.; Wunderlich, S. H.; Clososki, G. C.; Knochel, P. Eur. J. Org. Chem., 2009, 1781-1795. (e) Piller, F. M.; Knochel, P. Org. Lett., 2009, 11, 445-448. (f) Despotopoulou, C.; Klier, L.; Knochel, P. Org. Lett., 2009, 11, 3326-3329.

[30] Krasovskiy, A.; Krasovskaya, V.; Knochel, P. Angew. Chem. Int. Ed., 2006, 45, 29582961 (Angew. Chem., 2006, 118, 3024-3027).

[31] (a) For the magnesiation using $\mathrm{Bu}_{4} \mathrm{MgLi}_{2}$, see Ref. [29c]. (b) For the zincation using the in situ prepared mixture of (TMP) $)_{2} \mathrm{Zn}$ and LiTMP, see Ref. [19a]. (c) For the alumination using ${ }^{i} \mathrm{Bu}_{3} \mathrm{Al}(\mathrm{TMP}) \mathrm{Li}$, see Ref. [11a,e]. 
[32] Ethyl thiophene-2-carboxylate has previously been metallated using ${ }^{\mathrm{i}} \mathrm{Pr}_{2} \mathrm{NMgCl}$ (2 equiv) in THF at room temperature for $10 \mathrm{~min}$, and trapped with iodine to provide the same iodide in $77 \%$ yield. See Ref. [33].

[33] Shilai, M.; Kondo, Y.; Sakamoto, T. J. Chem. Soc., Perkin Trans. 1, 2001, 442-444.

[34] Dimetallated species have been previously described using zincate or manganate type bases: (a) Clegg, W.; Dale, S. H.; Hevia, E.; Hogg, L. M.; Honeyman, G. W.; Mulvey, R. E.; O'Hara, C. T. Angew. Chem. Int. Ed., 2006, 45, 6548-6550 (Angew. Chem., 2006, 118, 6698-6700); (b) Carrella, L. M.; Clegg, W.; Graham, D. V.; Hogg, L. M.; Kennedy, A. L.; Klett, J.; Mulvey, R. E.; Rentschler, E.; Russo, L. Angew. Chem. Int. Ed., 2007, 46, 4662-4666 (Angew. Chem., 2007, 119, 4746-4750); (c) Armstrong, D. R.; Clegg, W.; Dale, S. H.; Graham, D. V.; Hevia, E.; Hogg, L. M.; Honeyman, G. W.; Kennedy, A. R.; Mulvey, R. E. Chem. Commun., 2007, 598-600. See also Ref. [13].

[35] For the magnesiation using $\mathrm{Bu}_{4} \mathrm{MgLi}_{2}$, see Ref. [29c].

[36] (a) Blair, V. L.; Kennedy, A. R.; Klett, J.; Mulvey, R. E. Chem. Commun., 2008, 5426-5428. See also: (b) Graham, D. V.; Hevia, E.; Kennedy, A. R.; Mulvey, R. E.; O'Hara, C. T.; Talmard, C. Chem. Commun., 2006, 417-419.

[37] Snégaroff, K.; Chevallier, F.; Mongin, F., unpublished results.

[38] Quéguiner, G.; Marsais, F.; Snieckus, V.; Epsztajn, J. Adv. Heterocycl. Chem., 1991, 52, 187-304, and references cited therein.

[39] (a) Mongin, F.; Quéguiner, G. Tetrahedron, 2001, 57, 4059-4090. (b) Schlosser, M.; Mongin, F. Chem. Soc. Rev., 2007, 36, 1161-1172.

[40] Marzi, E.; Bigi, A.; Schlosser, M. Eur. J. Org. Chem., 2001, 1371-1376, and references cited therein.

[41] Awad, H.; Mongin, F.; Trécourt, F.; Quéguiner, G.; Marsais, F. Tetrahedron Lett., 2004, 45, 7873-7877. 
[42] Gros, P.; Choppin, S.; Mathieu, J.; Fort, Y. J. Org. Chem., 2002, 67, 234-237.

[43] For regioselective metallation reactions of 2,6-dichloropyridine and 2,6dibromopyridine at the 4 position, see Ref. [29d].

[44] (a) Krizan, T. D.; Martin, J. C. J. Org. Chem., 1982, 47, 2681-2682. (b) Krizan, T. D.; Martin, J. C. J. Am. Chem. Soc., 1983, 105, 6155-6157.

[45] Pletnev, A. A.; Tian, Q.; Larock, R. C. J. Org. Chem., 2002, 67, 9276-9287.

[46] (a) Cailly, T.; Fabis, F.; Lemaître, S.; Bouillon, A.; Rault, S. Tetrahedron Lett., 2005, 46, 135-137. (b) Cailly, T.; Fabis, F.; Bouillon, A.; Lemaître, S.; Sopkova, J.; de Santos, O.; Rault, S. Synlett, 2006, 53-56. Butyllithium in a mixture of THF and hexane has also been used, albeit in a low yield, to metallate 4-cyanopyridine at the 2 position: (f) Su, Y.-J.; Ko, C.-W. Chinese Pat. 2005, CN 1616471.

[47] Clososki, G. C.; Rohbogner, C. J.; Knochel, P. Angew. Chem. Int. Ed., 2007, 46, 76817684 (Angew. Chem., 2007, 119, 7825-7828).

[48] Cristau, H.-J.; Cellier, P. P.; Spindler, J.-F.; Taillefer, M. Eur. J. Org. Chem., 2004, 695-709.

[49] Bentabed-Ababsa, G.; Blanco, F.; Derdour, A.; Mongin, F.; Trécourt, F.; Quéguiner, G.; Ballesteros, R.; Abarca, B. J. Org. Chem., 2009, 74, 163-169.

[50] Jones, G. Adv. Heterocycl. Chem., 2002, 83, 1-70.

[51] (a) Jones, G.; Sliskovic, D. R. Tetrahedron Lett., 1980, 21, 4529-4530. (b) Jones, G.; Sliskovic, D. R. J. Chem. Soc., Perkin Trans. 1, 1982, 967-971.

[52] (a) Jones, G.; Pitman, M. A.; Lunt, E.; Lythgoe, D. J.; Abarca, B.; Ballesteros, R.; Elmasnaouy, M. Tetrahedron, 1997, 53, 8257-8268. (b) Abarca, B.; Ballesteros, R.; Elmasnaouy, M. Tetrahedron, 1998, 54, 15287-15292. 
[53] (a) Abarca, B.; Ballesteros, R.; Mojarred, F.; Jones, G.; Mouat, D. J. J. Chem. Soc., Perkin Trans. 1, 1987, 1865-1868. (b) Abarca, B.; Mojarred, F.; Jones, G.; Philips, C.; Ng, N.; Wastling, J. Tetrahedron, 1988, 44, 3005-3014.

[54] Concerning the deproto-lithiation of 3-cyano-[1,2,3]triazolo[1,5-a]pyridine, see: Jones, G.; Mouat, D. J.; Pitman, M. A. Tetrahedron, 1995, 51, 10969-10978.

[55] For the deproto-lithiation of 3-(2-pyridyl)- and 3-(2-thienyl)-[1,2,3]triazolo[1,5a]pyridine, see Ref. [51b]. For the deproto-lithiation of 3-(2-pyridyl)$[1,2,3]$ triazolo[1,5-a]pyridine (notably followed by trapping with iodine), see also: Abarca, B.; Alkorta, I.; Ballesteros, B.; Blanco, F.; Chadlaoui, M.; Elguero, J.; Mojarrad, F. Org. Biomol. Chem., 2005, 3, 3905-3910.

[56] Concerning metallation induced by an aza aromatic substituent, see: Mongin, F.; Rebstock, A.-S.; Trécourt, F.; Quéguiner, G.; Marsais, F. J. Org. Chem., 2004, 69, 6766-6771, and references cited therein.

[57] (a) Godard, A.; Turck, A.; Plé, N.; Marsais, F.; Quéguiner, G. Trends Heterocycl. Chem., 1993, 3, 16-29. (b) Turck, A.; Plé, N.; Quéguiner, G. Heterocycles, 1994, 37, 2149-2172. (c) Turck, A.; Plé, N.; Mongin, F.; Quéguiner, G. Tetrahedron, 2001, 57, 4489-4505. (d) Chevallier, F.; Mongin, F. Chem. Soc. Rev., 2008, 37, 595-609.

[58] Plé, N.; Turck, A.; Couture, K.; Quéguiner, G. J. Org. Chem., 1995, 60, 3781-3786.

[59] Imahori, T.; Kondo, Y. J. Am. Chem. Soc., 2003, 125, 8082-8083.

[60] (a) Boudet, N.; Reddy Dubbaka, S.; Knochel, P. Org. Lett., 2008, 10, 1715-1718. (b) Mosrin, M.; Knochel, P. Org. Lett., 2008, 10, 2497-2500.

[61] L'Helgoual'ch, J.-M.; Bentabed-Ababsa, G.; Chevallier, F.; Derdour, A.; Mongin, F. Synthesis, 2008, 4033-4035.

[62] Pieterse, K.; Lauritsen, A.; Schenning, A. P. H. J.; Vekemans, J. A. J. M.; Meijer, E. W. Chem. Eur. J., 2003, 9, 5597-5604. 
[63] Ellingson, R. C.; Henry, R. L. J. Am. Chem. Soc., 1949, 71, 2798-2800.

[64] Itoh, T.; Kato, S.; Nonoyama, N.; Wada, T.; Maeda, K.; Mase, T.; Zhao, M. M.; Song, J. Z.; Tschaen, D. M.; McNamara, J. M. Org. Process Res. Dev., 2006, 10, 822-828.

[65] See for example: (a) Tonsiengsom, F.; Miyake, F. Y.; Yakushijin, K.; Horne, D. A. Synthesis, 2006, 49-54; (b) Garg, N. K.; Stoltz, B. M. Tetrahedron Lett., 2005, 46, $2423-2426$.

[66] For recent examples, see: (a) Saito, R.; Machida, S.; Suzuki, S.; Katoh, A. Heterocycles, 2008, 75, 531-536; (b) Kojima, T.; Nishida, J.-i.; Tokito, S.; Tada, H.; Yamashita, Y. Chem. Commun., 2007, 1430-1432; (c) Marcaccio, M.; Paolucci, F.; Fontanesi, C.; Fioravanti, G.; Zanarini, S. Inorg. Chim. Acta, 2007, 360, 1154-1162; (d) Tsubomura, T.; Enoto, S.; Endo, S.; Tamane, T.; Matsumoto, K.; Tsukuda, T. Inorg. Chem., 2005, 44, 6373-6378.

[67] Mosrin, M.; Boudet, N.; Knochel, P. Org. Biomol. Chem., 2008, 6, 3237-3239.

[68] Dayaker, G.; Sreeshailam, A.; Chevallier, F.; Roisnel, T.; Radha Krishna, P.; Mongin, F. Chem. Commun., 2010, 46, 2862-2864.

[69] (a) Togni, A. Angew. Chem., Int. Ed. Engl., 1996, 35, 1475-1477 (Angew. Chem., 1996, 108, 1581-1583). (b) Arrayás, R. G.; Adrio, J.; Carretero, J. C. Angew. Chem. Int. Ed., 2006, 45, 7674-7715 (Angew. Chem., 2006, 118, 7836-7878).

[70] Long, N. Angew. Chem., Int. Ed. Engl., 1995, 34, 21-38 (Angew. Chem., 1995, 107, 37-56).

[71] van Staveren, D. R.; Metzler-Nolte, N. Chem. Rev., 2004, 104, 5931-5986.

[72] Atkinson, R. C. J.; Gibson, V. C.; Long, N. J. Chem. Soc. Rev., 2004, 33, 313-328.

[73] Stoll, A. H.; Mayer, P.; Knochel, P. Organometallics, 2007, 26, 6694-6697.

[74] Sanders, R.; Mueller-Westerhoff, U. T. J. Organomet. Chem., 1996, 512, 219-224. 
[75] Concerning the metallation of alkylferrocenes, see: Benkeser, R. A.; Bach, J. L. J. Am. Chem. Soc., 1964, 86, 890-895.

[76] See for example: Steffen, W.; Laskoski, M.; Collins, G.; Bunz, U. H. F. J. Organomet. Chem., 2001, 630, 132-138.

[77] Organocadmium reagents have been mainly prepared by reaction of organic halides with cadmium metal or by transmetallation: (a) Jones, P. R.; Desio, P. J. Chem. Rev., 1978, 78, 491-516; (b) O'Brien, P.; Malik, M. A. Sci. Synth., 2004, 3, 91-131.

[78] Gilman, H.; Nelson, J. F. Recl. Trav. Chim. Pays-Bas, 1936, 55, 518.

[79] (a) Shepard, A. F. J. Am. Chem. Soc., 1930, 52, 2083-2090. (b) Cass, O. W. U. S. Application No. 2430667, 1947.

[80] (a) Negishi, E.-i.; Takahashi, T.; Baba, S.; van Horn, D. E.; Okukado, N. J. Am. Chem. Soc., 1987, 109, 2393-2401; (b) Bumagin, N.; Ponomarev, A. B.; Beletskaya, I. P. Zh. Org. Khim., 1987, 23, 1345-1353. See also: (c) Miller, J. A.; Farrell, R. P. Tetrahedron Lett., 1998, 39, 7275-7278.

[81] Coulson, D. R. Inorg. Synth., 1972, 13, 121-123.

[82] Amatore, C.; Carré, E.; Jutand, A.; M'Barki, M. A. Organometallics, 1995, 14, 18181826.

[83] Frisch, M. J.; et al. Gaussian 03, revision E.01; Gaussian, Inc., Wallingford CT, 2004.

[84] (a) Becke, A. D. Phys. Rev., 1988, A38, 3098-3100. (b) Becke, A. D. J. Chem. Phys., 1993, 98, 1372-1377. (c) Becke, A. D. J. Chem. Phys., 1993, 98, 5648-5652. (d) Lee, C.; Yang, W.; Parr, R. G. Phys. Rev., 1988, B37, 785-788.

[85] Schäfer, A.; Horn, H.; Ahlrichs, R. J. Chem. Phys., 1992, 97, 2571-2577.

[86] (a) Fukui, K. Acc. Chem. Res., 1981, 14, 363-368. (b) Ishida, K.; Morokuma, K.; Komornicki, A. J. Chem. Phys., 1977, 66, 2153-2156. (c) Gonzalez, C.; Schlegel, H. 
B. J. Chem. Phys., 1989, 90, 2154-2161. (d) Schlegel, H. B.; Gonzalez, C. J. Phys. Chem., 1990, 94, 5523-5527.

[87] Shannon, M. Heavy Metal Poisoning in Clinical Management of Poisoning and Drug Overdose, $3^{\text {rd }}$ ed. (Eds: Haddad, L. M.; Shannon, M.; Winchester, J. F.), 1998. 